Research Paper

\title{
Small molecules for cell reprogramming: a systems biology analysis
}

\author{
Anna Knyazer ${ }^{1,}$, Gabriela Bunu ${ }^{2, *}$, Dmitri Toren², Teodora Bucaciuc Mracica², Yael Segev, \\ Marina Wolfson ${ }^{1}$, Khachik K. Muradian ${ }^{3}$, Robi Tacutu², Vadim E. Fraifeld ${ }^{1,3}$ \\ ${ }^{1}$ The Shraga Segal Department of Microbiology, Immunology and Genetics, Center for Multidisciplinary Research \\ on Aging, Ben-Gurion University of the Negev, Beer-Sheva, Israel \\ ${ }^{2}$ Systems Biology of Aging Group, Institute of Biochemistry of the Romanian Academy, Bucharest, Romania \\ ${ }^{3}$ D.F. Chebotarev Institute of Gerontology of National Academy of Medical Sciences of Ukraine, Kiev, Ukraine \\ *Equal contribution
}

Correspondence to: Robi Tacutu, Vadim E. Fraifeld; email: robi.tacutu@gmail.com, https://orcid.org/0000-0001-5853-2470; vadim.fraifeld@gmail.com, https://orcid.org/0000-0002-4525-0535

Keywords: cell reprogramming, chemically-induced pluripotency, chemical-protein interactions, protein-protein interaction networks, longevity pathways

Received: August 6, $2021 \quad$ Accepted: November 24, $2021 \quad$ Published: December 17, 2021

Copyright: (C) 2021 Knyazer et al. This is an open access article distributed under the terms of the Creative Commons Attribution License (CC BY 3.0), which permits unrestricted use, distribution, and reproduction in any medium, provided the original author and source are credited.

\section{ABSTRACT}

If somatic stem cells would be able to maintain their regenerative capacity over time, this might, to a great extent, resolve rejuvenation issues. Unfortunately, the pool of somatic stem cells is limited, and they undergo cell aging with a consequent loss of functionality. During the last decade, low molecular weight compounds that are able to induce or enhance cell reprogramming have been reported. They were named "Small Molecules" (SMs) and might present definite advantages compared to the exogenous introduction of stemness-related transcription factors (e.g. Yamanaka's factors). Here, we undertook a systemic analysis of SMs and their potential gene targets. Data mining and curation lead to the identification of 92 SMs. The SM targets fall into three major functional categories: epigenetics, cell signaling, and metabolic "switchers". All these categories appear to be required in each SM cocktail to induce cell reprogramming. Remarkably, many enriched pathways of SM targets are related to aging, longevity, and age-related diseases, thus connecting them with cell reprogramming. The network analysis indicates that SM targets are highly interconnected and form protein-protein networks of a scale-free topology. The extremely high contribution of hubs to network connectivity suggests that (i) cell reprogramming may require SM targets to act cooperatively, and (ii) their network organization might ensure robustness by resistance to random failures. All in all, further investigation of SMs and their relationship with longevity regulators will be helpful for developing optimal SM cocktails for cell reprogramming with a perspective for rejuvenation and life span extension.

\section{INTRODUCTION}

The pool of adult stem cells is limited, and they undergo cell aging with a consequent loss of functionality [1-3]. This limits the application of adult stem cells for cell replacement therapy. Induced pluripotency (iP), a state where somatic differentiated cells become functionally similar to embryonic stem cells (ESC), may serve as an alternative solution. The breakthrough findings of iP, first discovered by Takahashi and Yamanaka in 2006, by ectopic overexpression of four stemness-related transcription factors (TFs: Oct3/4, Sox2, Klf4, and c-Myc; OSKM in short), in mouse fibroblasts [4], and then repeated in human fibroblasts [5], proved the plasticity potential of differentiated cells to rejuvenate back to the ESC- 
like state. Since then, various combinations of transcription factors for iP have been proposed [6-8]. Still, the exogenous introduction of transgenes provides a low yield, both in vitro and in vivo, and may have undesirable complications, including tumorigenicity (reviewed by [3]).

Recently, a number of small molecules (SMs) that are able to induce or enhance pluripotency have been discovered [9-11]. They have definite advantages and could be used for iP as a much safer alternative [12]. First of all, cell dedifferentiation activity could be finetuned by varying the concentrations of SM. When needed, the application of lineage-alternating SMs could induce cell differentiation and inhibit cell proliferation. Moreover, SMs are distinguished by nonimmunogenicity, cost-efficiency, minimal residual effects on the genome, and feasibility of in vivo application [13, 14]. Consequently, this strategy may have great potential in clinical practice. With this in mind, the major goal of this study was to provide a systems biology view of the SMs, thus supporting researchers with a potential basis for the optimal selection of drugs for cell reprogramming.

In this in silico study we performed: (i) a comprehensive data mining of SMs; (ii) the characterization of SMs and SM cocktails, including assessing their protein targets and possible interactions between them; (iii) the analysis of pathways targeted by SMs, (iv) the comparison of targets and pathways of SM cocktails with those of the OSKM TFs, and (v) screening for SMs as human metabolites.

\section{RESULTS}

\section{General characterization of SMs and SM cocktails for cell reprogramming}

We first compiled a full list of SMs established thus far, based on a keyword meta-analysis of the literature. Comprehensive data mining with subsequent curation (see Methods) resulted in a total of 92 chemical compounds (Supplementary Table 1) that can either induce or enhance pluripotency, alone or in combination with TFs. These compounds for chemical reprogramming were named "Small Molecules" (SMs) because of their relatively low molecular weight [9], which ranges from $42.4 \mathrm{~g} / \mathrm{mol}$ ( $\mathrm{LiCl}$ ) to $914.2 \mathrm{~g} / \mathrm{mol}$ (Rapamycin). The vast majority of SMs represent organic compounds belonging to various chemical classes; however, among SMs were also several inorganic compounds (e.g., Lithium salts).

The analysis of the basic biological activities of the collected SMs revealed that they fall into three major categories (Figure 1 and Supplementary Tables 2-5): (i) signaling modifiers, (ii) epigenetic modifiers, and (iii) metabolic modifiers. It should also be mentioned that some SMs do not fall into definite categories or belong to more than one functional category.

The SMs with signaling activity represent the largest group (51 out of 92 compounds; 55.4\%; Supplementary Table 2), followed by epigenetic $(\mathrm{n}=26 ; 28.3 \%$; Supplementary Table 3$)$ and metabolic modifiers $(\mathrm{n}=7$; 7.6\%; Supplementary Table 4). The most "popular"

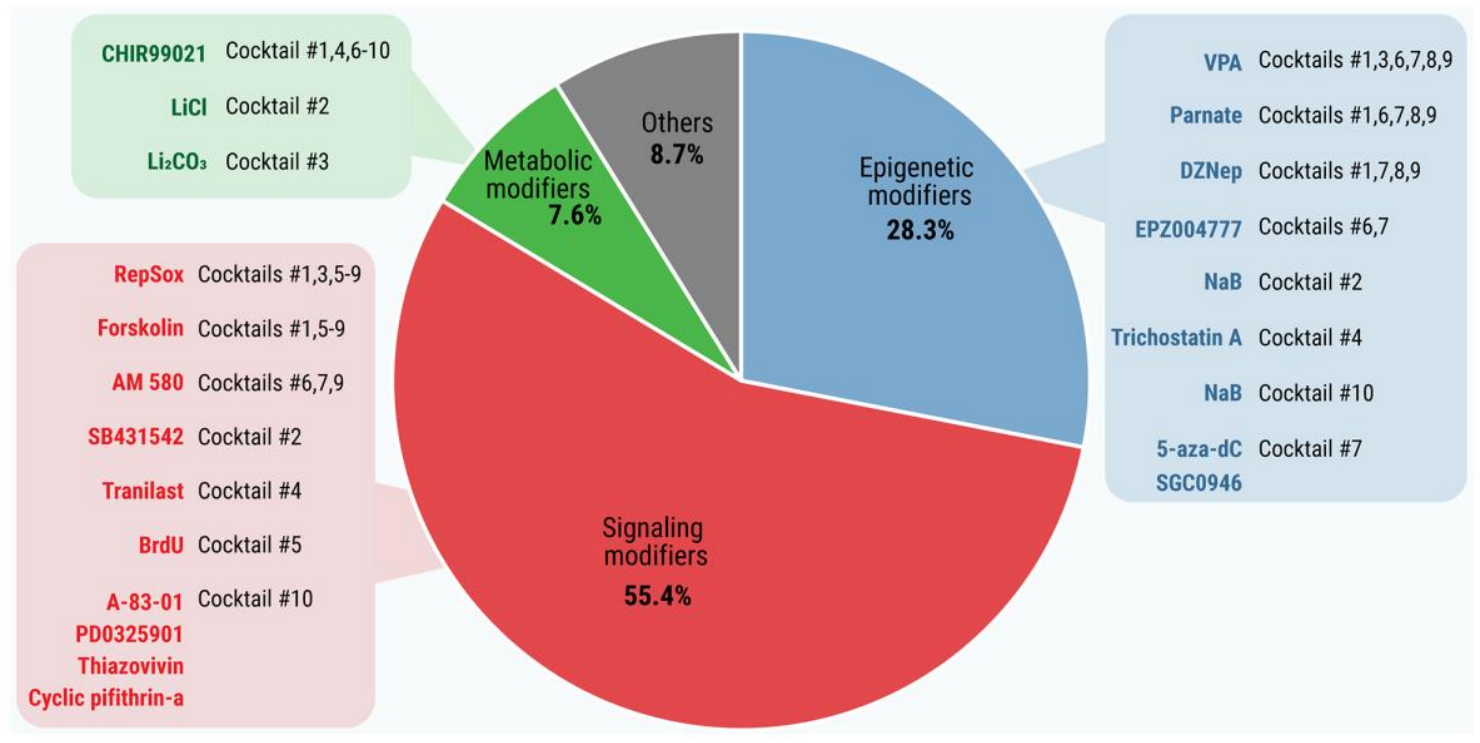

Figure 1. Distribution of SMs by functional categories. The basic biological activities of all SMs that induce or enhance pluripotency $(n=92)$ were extracted from the STITCH online tool, PubChem database and scientific literature. Functional categories of SMs were based on Gene Ontology Resource. 
(i.e., most frequently used in SM cocktails) signaling modifiers include inhibitors of TGF $\beta$ and Hedgehog signaling, both involved in cell differentiation $[15,16]$. In the epigenetic category, most SMs inhibit either methyltransferases (HMTs and DNMTs, 9 and 6, respectively) or HDACs $(n=4)$. Other molecules possess either dual activity (HDAC inducers and/or inhibitors, $\mathrm{n}=3$ ) or combined (inhibition of HMT+DNMT or DNMT+HDAC) activities. This, respectively, shifts the condensed form of chromatin (heterochromatin) towards a relaxed state (euchromatin) or decreases the level of DNA methylation, thereby ensuring more DNA to be available for transcription. Lastly, metabolic modifiers switch the metabolism from oxidative phosphorylation towards glycolysis, mostly through the inhibition of the GSK3 enzyme [17]. Other SMs ( $\mathrm{n}=8 ; 8.7 \%$; Supplementary Table 5) include antioxidants, regulators of calcium transport, autophagy, etc.

To date, several combinations of SMs have been tested for cell reprogramming activity. Of them, $10 \mathrm{SM}$ cocktails have been established. Their compositions, which vary from three [10] to ten [18] compounds, are presented in Supplementary Table 6. The common denominator for all these cocktails is that they are able to induce cell reprogramming, either full (pluripotent state) or partial (multipotent/progenitor cells), without transfection of stemness-related TFs.

A comparison between the cocktails revealed 22 nonredundant chemicals, presented in Table 1 . It should be emphasized that each cocktail contains at least one SM from each of the epigenetic, signaling or metabolic activity categories, which coincide well with the results presented above. Of note, TGF $\beta$ inhibitors are presented in all cocktails. In particular, RepSox, which can replace Sox 2 [19], is included in 7 of the 10 cocktails, and in the other three, the TGF $\beta$ inhibitors are replaced by SB431542 or Tranilast, both able to replace Sox2 [10, 19], or by A-83-01 [20]. Another frequently-used signaling modifier included Forskolin (found in six cocktails) or BrdU (in Cocktail 5). The mentioned compounds can replace Oct4 $[9,21]$ (see Supplementary Table 1). The nuclear RAR $\alpha$ selective agonist AM 580 and the synthetic retinoic acid receptor ligand TTNPB affecting the retinoic acid signaling pathway are used in four cocktails. As seen in Table 1, the GSK3 inhibitors (CHIR99021, $\mathrm{LiCl}$ or $\mathrm{Li}_{2} \mathrm{CO}_{3}$ ) which promote glycolysis are mandatory components of each reprogramming cocktail. Finally, all the cocktails include one or more epigenetic modifiers: HDAC inhibitors (VPA, $\mathrm{NaB}$, Trichostatin A), DNMT inhibitors (5-aza-dC), the inhibitor of LSD1 acting on histone H3 (Parnate), and the inhibitors of histone methyltransferases (DZNep, EPZ004777, SGC0946). The common SMs are presented in the reprogramming cocktails in descending order: CHIR99021 $=$ RepSox $(n=7)$, VPA $=$ Forskolin $(n=6)$, Parnate $(\mathrm{n}=5)$, DZNep $(\mathrm{n}=4)$, AM $580(\mathrm{n}=3)$, EPZ004777 $(\mathrm{n}=2)$; other SMs are found only in one cocktail (see Table 1).

\section{KEGG pathways enrichment analysis of SM targets}

To get further insight into the mechanisms of chemically-induced reprogramming, we carried out an enrichment analysis for SM protein targets. For that purpose, we first used the STITCH database (https://pubmed.ncbi.nlm.nih.gov/26590256/) for extracting the chemical-protein interactions. Then, using the DAVID bioinformatics tools [22], we determined the enriched KEGG pathways of the found SM protein targets (in total, 1023). Figure 2 depicts the most enriched KEGG categories ( $p<0.001$ after Benjamini correction, with at least two-fold enrichment) among SM targets (for a full list of the enriched pathways, see Supplementary Table 7).

The most significantly enriched KEGG pathways include pathways associated with regulation of longevity such as mTOR signaling $(\mathrm{p}=9.1 \mathrm{E}-18)$, AMPK signaling $(\mathrm{p}=5.7 \mathrm{E}-17)$, Insulin signaling $(\mathrm{p}=$ $2.3 \mathrm{E}-13)$, FoxO signaling $(\mathrm{p}=4.2 \mathrm{E}-23)$, and pathways involved in cell-cell and cell-extracellular matrix interactions (Focal adhesion, $\mathrm{p}=3.7 \mathrm{E}-13$, Adherens junction, $\mathrm{p}=5.4 \mathrm{E}-06)$. Also, $\mathrm{SM}$ targets are overpresented in the signaling pathways associated with age-related diseases, including different types of cancer, type II diabetes mellitus $(\mathrm{p}=7.7 \mathrm{E}-08)$, amyotrophic lateral sclerosis $(\mathrm{p}=2.3 \mathrm{E}-04)$, and Alzheimer's disease $(\mathrm{p}=2.5 \mathrm{E}-03)$. Among the enriched pathways are numerous growth-promoting pathways, cell survival (PI3K-Akt, $\mathrm{p}=3.9 \mathrm{E}-19)$ or cell death (Apoptosis, $\mathrm{p}=$ 1.7E-18) signaling. Many enriched pathways are related to immune and inflammatory responses. Among them are the pathways related to innate immunity (Toll-like receptor signaling pathway, $\mathrm{p}=1.8 \mathrm{E}-09 ; \mathrm{NK}$-cell mediated cytotoxicity, $\mathrm{p}=2.6 \mathrm{E}-06$ ), specific immune responses ( $\mathrm{T}$ cell receptor signaling pathway, $\mathrm{p}=5.3 \mathrm{E}$ 15 ; B cell receptor signaling pathway, $\mathrm{p}=2.1 \mathrm{E}-07$ ), and inflammatory signaling (Chemokine signaling pathway, $\mathrm{p}=1.5 \mathrm{E}-13$; Adipocytokine signaling pathway, $\mathrm{p}=$ 2.1E-11), etc. Not surprisingly, the enriched pathways include regulation of cell cycle $(\mathrm{p}=3.5 \mathrm{E}-09)$, cell differentiation (Neurotrophins, $\mathrm{p}=3.3 \mathrm{E}-18$; TGF $\beta$ signaling, $\mathrm{p}=9.4 \mathrm{E}-06$ ), and Signaling pathways regulating pluripotency of stem cells $(\mathrm{p}=2.8 \mathrm{E}-06)$.

\section{Network analysis of SM targets}

To further evaluate to what extent the SM targets interact between themselves, we determined their 
Table 1. Non-redundant SMs for reprogramming cocktails and their main bioactivities.

\begin{tabular}{|c|c|c|c|c|c|c|c|c|c|c|c|}
\hline \multirow{2}{*}{ SM } & \multirow{2}{*}{ Main bioactivity } & \multicolumn{10}{|c|}{ Cocktail } \\
\hline & & 1 & 2 & 3 & 4 & 5 & 6 & 7 & 8 & 9 & 10 \\
\hline CHIR99021 & GSK3 inhibitor & & & & & & & & & & \\
\hline RepSox & $\begin{array}{c}\text { TGF } \beta \text { inhibitor } \\
\text { [can replace Sox2] }\end{array}$ & & & & & & & & & & \\
\hline VPA & HDAC inhibitor & & & & & & & & & & \\
\hline Forskolin & $\begin{array}{l}\text { cAMP activator } \\
\text { [can replace Oct4] }\end{array}$ & & & & & & & & & & \\
\hline Parnate & Inhibitor of LSD1 acting on histone $\mathrm{H} 3$ & & & & & & & & & & \\
\hline DZNep & $\begin{array}{c}\text { Inhibitor of HMT EZH } \\
\text { and SAH synthesis }\end{array}$ & & & & & & & & & & \\
\hline AM 580 & $\begin{array}{l}\text { Nuclear RAR } \alpha \\
\text { selective agonist }\end{array}$ & & & & & & & & & & \\
\hline EPZ004777 & $\begin{array}{l}\text { DOT1L histone (H3K79) } \\
\text { methyltransferase inhibitor }\end{array}$ & & & & & & & & & & \\
\hline $\mathrm{NaB}$ & HDAC inhibitor & & & & & & & & & & \\
\hline TTNPB & $\begin{array}{l}\text { Synthetic retinoic acid } \\
\text { receptor ligand }\end{array}$ & & & & & & & & & & \\
\hline BrdU & $\begin{array}{l}\text { Synthetic analog of thymidine [can } \\
\text { replace Oct } 4 \text { ] }\end{array}$ & & & & & & & & & & \\
\hline $\mathrm{LiCl}$ & GSK3 inhibitor & & & & & & & & & & \\
\hline SB431542 & $\begin{array}{c}\text { TGF } \beta \text { inhibitor } \\
\text { [can replace RepSox] }\end{array}$ & & & & & & & & & & \\
\hline Tranilast & $\begin{array}{c}\text { TGF } \beta \text { inhibitor } \\
\text { [can replace RepSox] }\end{array}$ & & & & & & & & & & \\
\hline Trichostatin A & HDAC inhibitor & & & & & & & & & & \\
\hline $\mathrm{Li}_{2} \mathrm{CO}_{3}$ & GSK3 inhibitor & & & & & & & & & & \\
\hline 5'-aza-dC & DNMT inhibitor & & & & & & & & & & \\
\hline SGC0946 & $\begin{array}{l}\text { DOT1L histone (H3K79) } \\
\text { methyltransferase inhibitor }\end{array}$ & & & & & & & & & & \\
\hline $\begin{array}{l}\text { Cyclic } \\
\text { pifithrin-a }\end{array}$ & p53 inhibitor & & & & & & & & & & \\
\hline A-83-01 & $\begin{array}{l}\text { TGF-beta receptor } \\
\text { inhibitor }\end{array}$ & & & & & & & & & & \\
\hline Thiazovivin & Rho Kinase (ROCK) inhibitor & & & & & & & & & & \\
\hline PD0325901 & $\begin{array}{l}\text { Potent MKK1 (MEK1) and MKK2 } \\
\text { (MEK2) inhibitor }\end{array}$ & & & & & & & & & & \\
\hline
\end{tabular}

protein-protein interactions (PPIs), annotated in the BioGRID database [23]. These data are currently available for 991 out of 1023 SM target proteins. The analysis revealed that many of these targets interact with each other and exhibit multiple PPIs (in total, 6072 interactions). Remarkably, a significant fraction of the interacting SM targets (851 out of 991 proteins; 85.8\%) forms a continuous network between themselves 
(Figure 3A). This fraction is significantly higher than expected by chance, i.e., higher than for the same number of randomly selected proteins with annotated PPIs (Figure 3B) (random sampling, mean \pm SD: $52.8 \pm$ $3.5 \%$; z-score for observed value: 9.37 ).
Next, we aimed to understand the topology of the constructed network. To address this point, we calculated the distribution of node connectivity. The regression equation in Figure 3C $\left(P(k)=221 \times k^{-1.16}\right)$ follows a power-law distribution of connectivity and

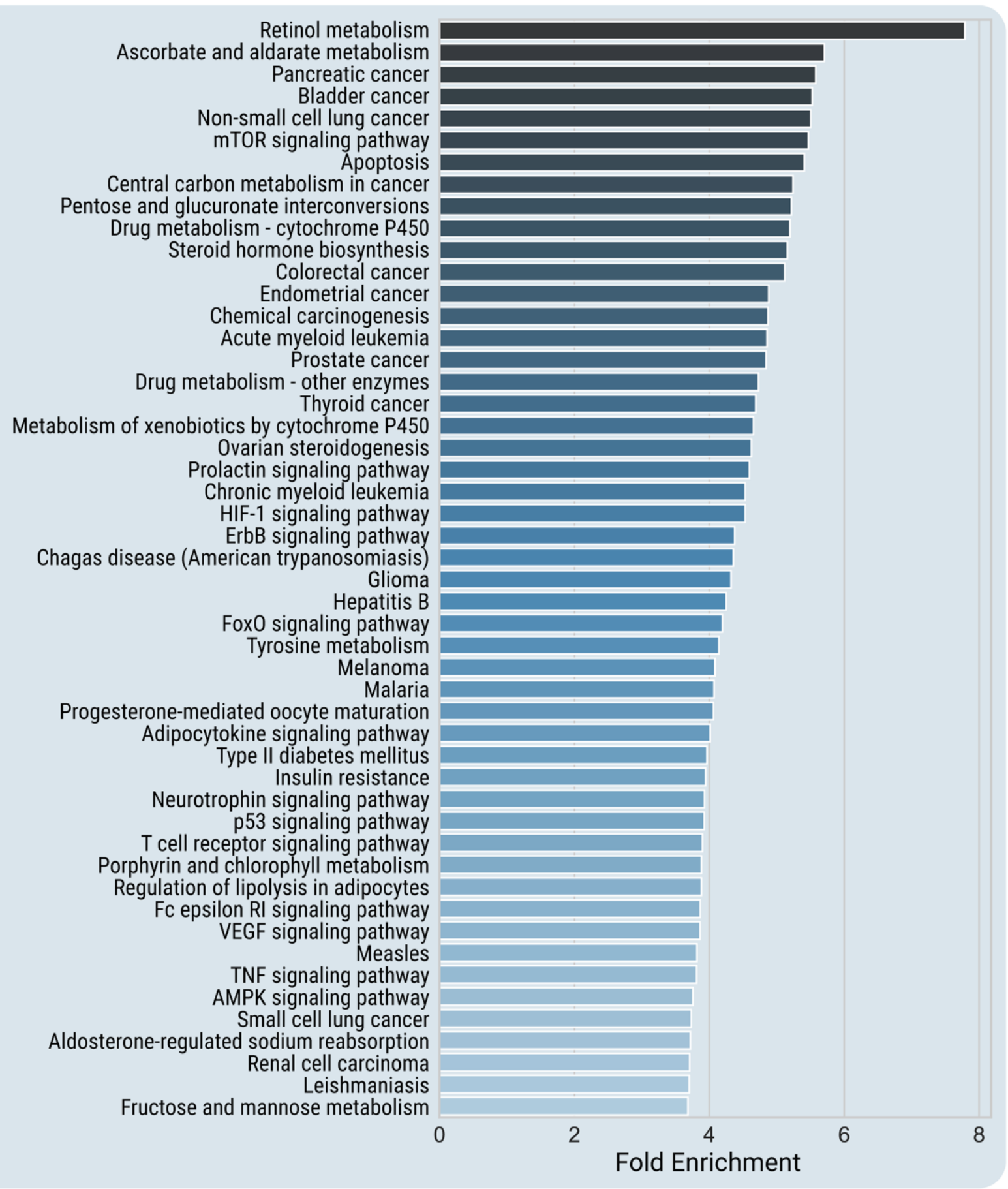

Figure 2. Top enriched KEGG pathways of SM protein targets. Enriched pathways at high confidence ( $p<0.001$ after Benjamini correction, with at least two-fold enrichment) are presented. Because of visualization limitations, only the top-most enriched 50 pathways are included in the figure. For a full list of the enriched pathways, see Supplementary Table 7, and for the enriched pathways for each SM cocktail, see Supplementary Table 8. 


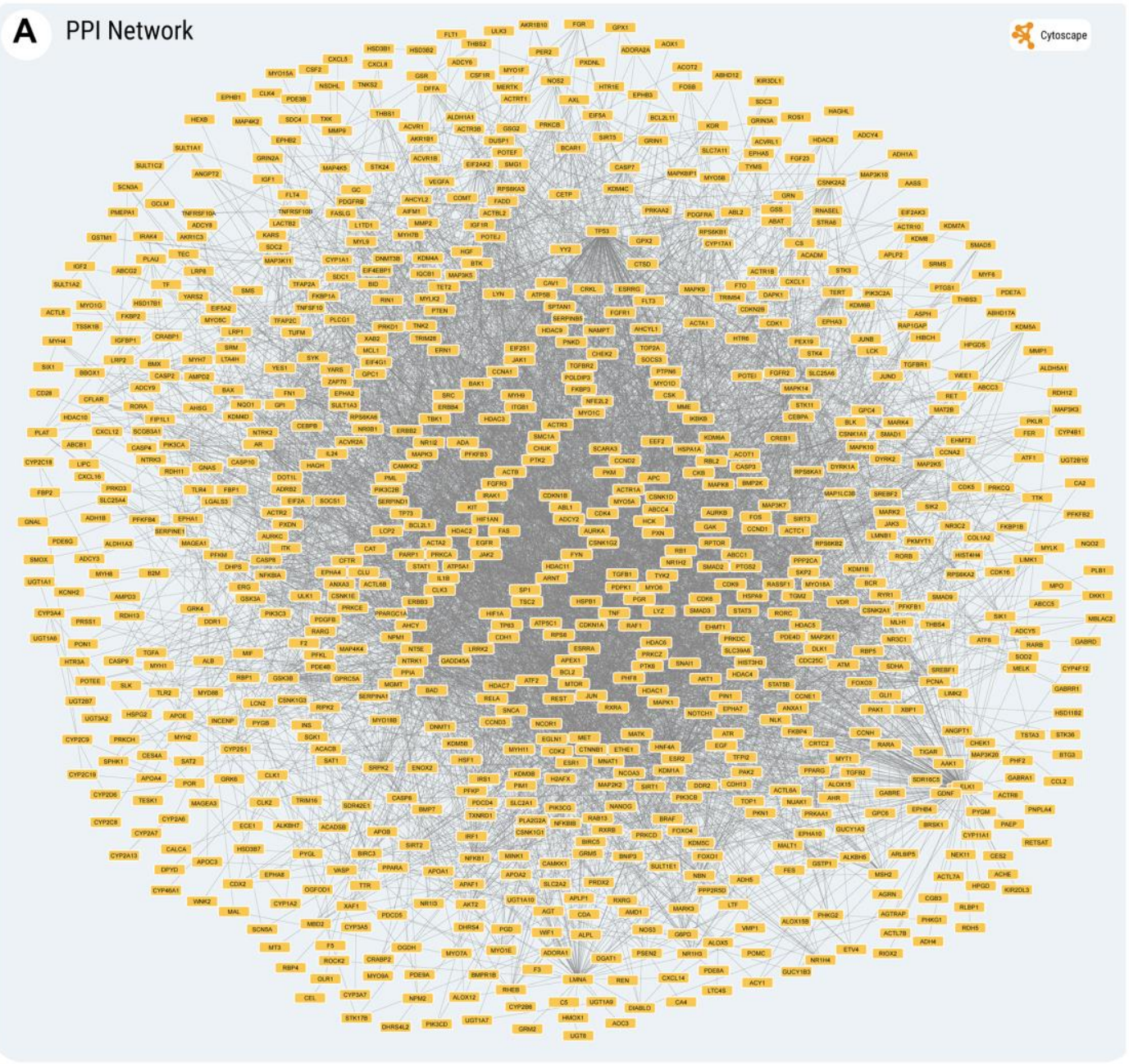

B Simulation

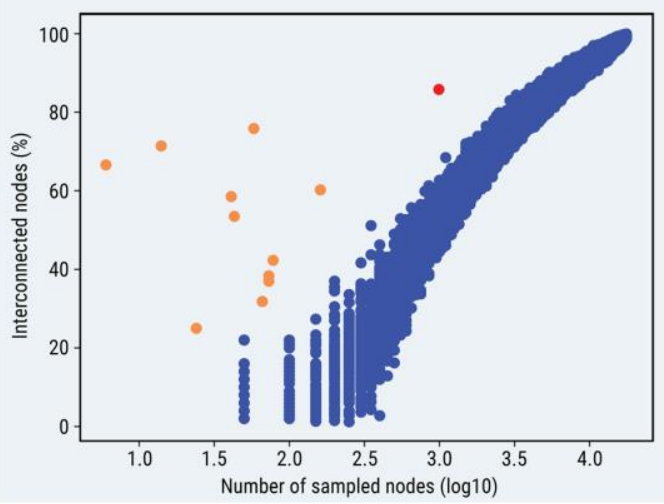

C Log-log degree distribution

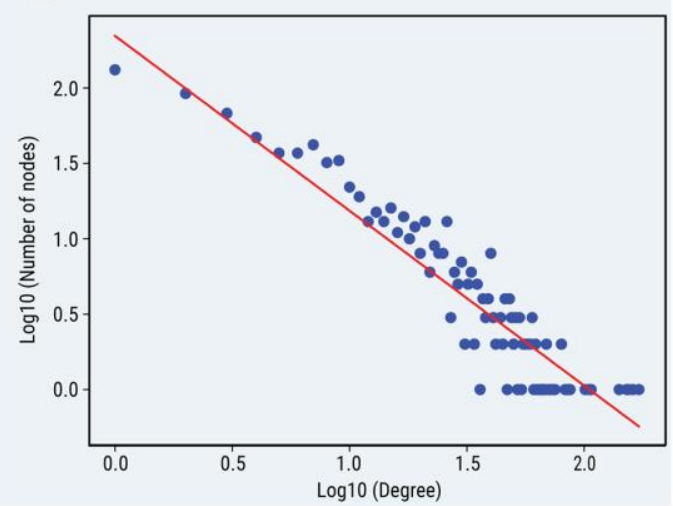

Figure 3. (A) Graphical output of the PPI network of the entire set of SMs' targets. (B) Simulation of expected interconnectivity given the size of a random sample. The observed interconnectivity of SMs' gene targets in the interactome, depicted by the red dot in the scatter plot and the observed interconnectivity of cocktails' gene targets, depicted by the orange dots, can be compared to the percentage of interconnected nodes (on the Y-axis), found in the largest continuous component of the network, for randomly sampled node sets. The plot shows the sampling of subsets of random interactome nodes, of various sizes (represented in a log10 scale on the X-axis, from 50 to 17,600 nodes). For each step, the interconnectivity was computed 100 times. Simulations were performed only for samples larger than 50 nodes, because of the increased variability of very small node sets. (C) The log-log plot of $P(k)$ against $k$, illustrating scale-free topology of the network (for details, see the text and Methods). For all the nodes and edges in the network see Supplementary Table 9. (A, C) The construction and display of the network and the degree distribution regression were performed using Cytoscape, which pulls physical PPIs data determined in vitro and in vivo from the BioGRID database. 
indicates that the PPI network of SM targets has a scalefree topology, with an extremely high contribution of hubs to the average network connectivity.

Using the same approach, we built the chemical-protein interaction and PPI networks for the ten SM cocktails used thus far for chemical reprogramming (see Supplementary Table 6). As seen in Figure 4 and Supplementary Figures 1-9, the total number of annotated protein targets in SM cocktails varied from 6 (Cocktail 10) to 174 (Cocktail 7), mostly falling around 50. In all cases, the fraction of proteins forming a continuous PPI network was extremely high (from $25 \%$ to $75.9 \%$ ) for such small sizes of protein sets (Figure 3B), z-scores computed after random sampling being between 5.33 and 30. Collectively, the results obtained indicate that the SM targets are highly interconnected.

\section{Comparison of targets and pathways of SM cocktails with Yamanaka's factors}

It seems plausible that the cocktails for chemical cell reprogramming and TFs for iP, specifically Yamanaka's factors (OSKM), have common targets (Figure 5A).
However, their comparison showed that only the gene targets of Cocktail \#7 (15 targets; p = 0.0033) overlap significantly with the targets of a "classical" combination of iP transcription factors (Figure 5A). Other cocktails overlap insignificantly $(p>0.05)$ with OSKM. Of note, Cocktail \#7 has much more targets than any other cocktail for chemical reprogramming. In contrast to specific targets, several cocktails (\#2, 3, 4 and 7) have significantly overlapped pathways with OSKM (Figure 5B). As seen in Table 2, most common pathways are cancer-related. Though not reaching the level of significance, the common pathways of other cocktails (\#1, 5, 6, 8, 9 and 10) are also cancer-related.

\section{SMs as human metabolites}

Most SMs are artificially synthesized chemicals. Of special interest is whether among the SMs are compounds that are natural (human) metabolites or their analogs. Overlapping the 92 SMs with the molecules found in the Human Metabolome Database - HMDB [24] gives a positive answer to this question: 28 compounds from the SM list are also found in HMDB (Table 3). The overlap is statistically extremely significant

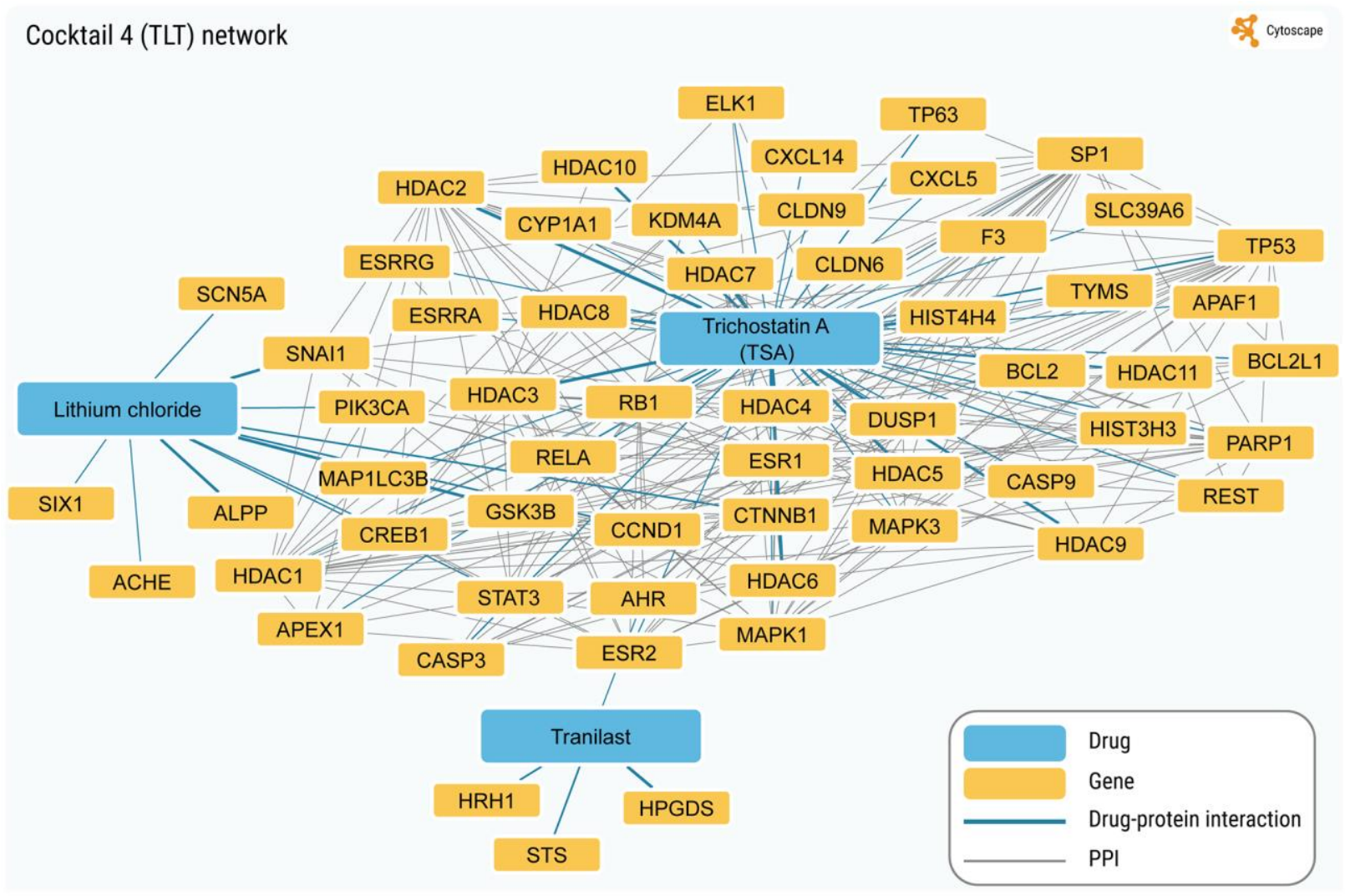

Figure 4. The network with the highest interconnectivity (corresponding to the TLT cocktail). In total, 58 protein targets are in the network. Continuous network without taking into account drug connectivity (chemical-protein interactions) includes 44 genes/proteins (75.9\%; values for random sampling (mean \pm SD): $4.5 \pm 2.4$; z-score for observed value: 30.03 ). 
( $\mathrm{p}=9.7 \mathrm{E}-83$ ). For example, among SMs are essential natural metabolites $(n=8)$ including several vitamins (A, C, D), molecules belonging to fatty acids and their derivatives $\left(\mathrm{NaB}, \mathrm{PGE}_{2}\right)$, organooxygen (Fru-2,6-P2) and organonitrogen (Spermidine) compounds, and prenol lipids (Retinoic acid). Other "natural" SMs represent nutrients that integrate into the human body when consuming products of plant metabolism $(\mathrm{n}=$ 11). Interestingly, several of these compounds (e.g. EGCG, 7-hydroxyflavone, apigenin, curcumin, quercetin, resveratrol) are components of plant extracts that have been already shown to improve healthspan, in particular stress resistance and cognitive abilities [25]. Several SMs are medications, which under specific conditions can be found in the human body. Although they are not the products of human metabolism or essential nutrients, most of them are analogs of natural metabolites. For example, 5'-azaC or 5'-Aza-2'-deoxycytidine are analogs of the nucleoside cytidine; $\mathrm{N}$-acetyl-cysteine is metabolized into L-cysteine, a precursor to the biologic antioxidant glutathione; Valproic acid (VPA) is a branched shortchain fatty acid derived from the naturally occurring Valeric acid [26].

\section{A Targets}

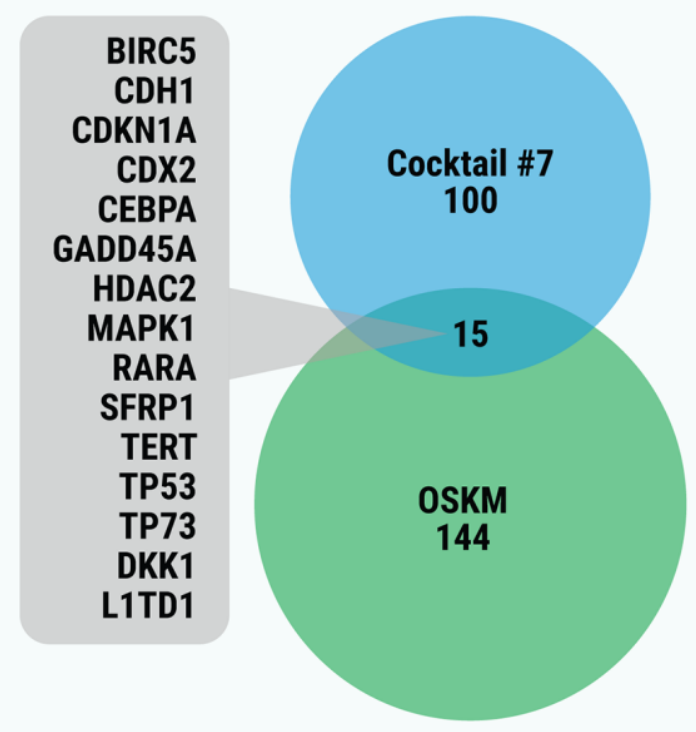

Furthermore, using STITCH tools [27], we found another 963 molecules that are similar (based on the STITCH drug similarity score) to the SMs that induce or enhance pluripotency, of them, 210 compounds (data not shown) are present in the Human Metabolome Database [24]. Among these compounds are neurotransmitters (serotonin, dopamine and GABA), fatty acids, and their derivatives involved in energy metabolism, such as citric acid, succinate and lactate. We determined the targets of these 210 chemicals, of the abovementioned eight human essential natural metabolites, and then compared them with the targets of all collected SMs $(n=1,023)$ and SM cocktails $(n=$ 204) (Supplementary Table 10). As seen in the Supplementary Table 10, there is an extremely significant $(\mathrm{p}<\mathrm{E}-25$, Fisher test) overlap between the targets of the 210 SM-like chemicals $(n=4,614)$ and the targets of all SMs or the targets of SM cocktails. The common targets cover more than 76\% (782 of 1023 targets) and 65\% (132 out of 204 targets), respectively. Also, an extremely significant overlap was found for the targets of the abovementioned 8 human natural metabolites $(n=318)$ and the targets of SM cocktails $(21 \%, 43$ of 204).
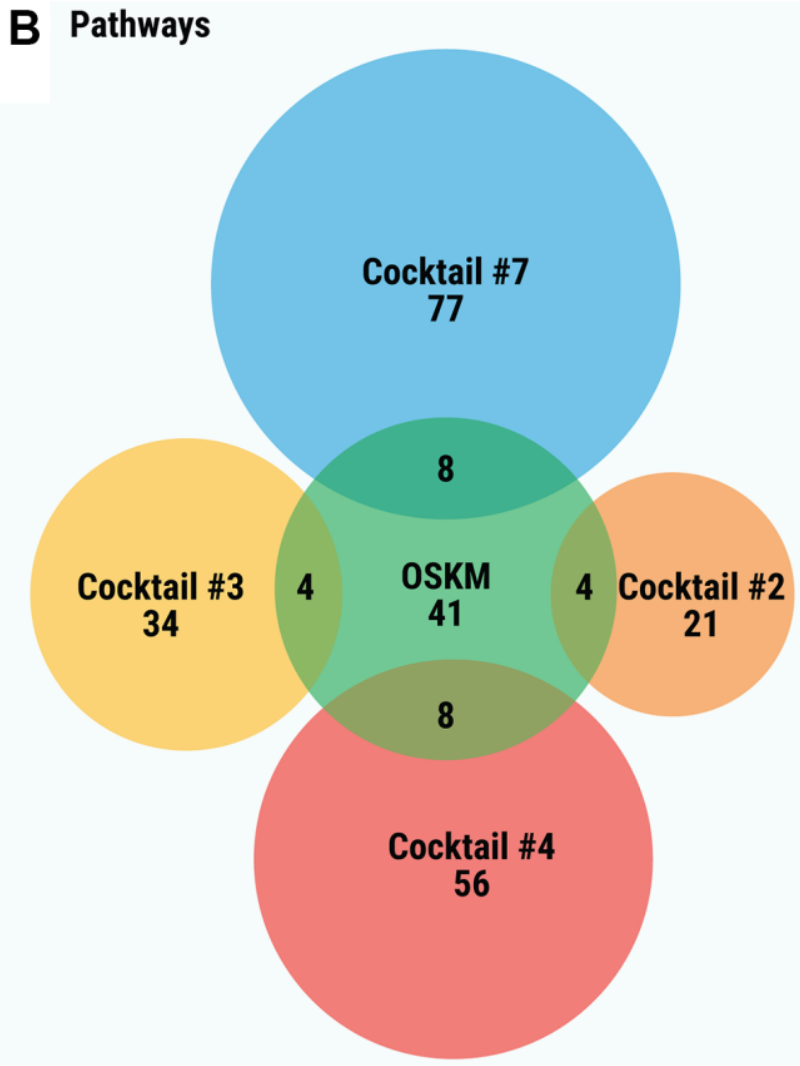

Figure 5. (A) Venn diagram of the gene targets of OSKM significantly overlapping with gene targets of cocktails. (B) Venn diagram of significantly overlapping enriched pathways for gene targets of SM cocktails and of OSKM. In order to simplify the figure, only statistically significant overlaps between OSKM and cocktails are displayed. Overlaps between pairs of cocktails are not shown. 
Table 2. Overlapping pathways for targets of SM cocktails and OSKM.

\begin{tabular}{|c|c|c|c|c|c|c|c|c|c|c|}
\hline \multirow{2}{*}{ Pathways } & \multicolumn{10}{|c|}{ Cocktails } \\
\hline & $\# 1$ & $\# 2$ & \#3 & \#4 & \#5 & \#6 & \#7 & $\# 8$ & \#9 & $\# 10$ \\
\hline Pathways in cancer & & $*$ & $*$ & $*$ & & & $*$ & & & \\
\hline Chronic myeloid leukemia & & $*$ & $*$ & $*$ & & & $*$ & & & \\
\hline Prostate cancer & & $*$ & & $*$ & & & $*$ & & & \\
\hline Bladder cancer & & & & & & & $*$ & & & \\
\hline Small cell lung cancer & & & & $*$ & & & & & & \\
\hline Viral carcinogenesis & & & $*$ & $*$ & & & $*$ & & & \\
\hline HTLV-I infection & & $*$ & & $*$ & & & $*$ & & & \\
\hline Hepatitis B & & & $*$ & $*$ & & & $*$ & & & \\
\hline Epstein-Barr virus infection & & & & $*$ & & & & & & \\
\hline p53 signaling pathway & & & & & & & $*$ & & & \\
\hline
\end{tabular}

Dark gray color with $\left(^{*}\right)$ depicts overlaps with $p<0.05$. Light gray depicts the pathways with insignificant overlaps $(p>0.05)$.

\section{DISCUSSION}

Until now, the selection of SMs for chemically-induced pluripotency or cell reprogramming was done mainly on an empirical basis, and no analysis of SMs and their targets has been undertaken. Several reviews published in the past [28-32] focused on specific aspects of SMs but none of them provided a "systemic" view. Our comprehensive data mining with subsequent data curation revealed $92 \mathrm{SMs}$ that have been reported in connection to cell reprogramming. Most of the SMs were primarily used as enhancers of iP, i.e., for increasing the efficiency of cocktails containing TFs (e.g., Yamanaka's factors) $[30,33,34]$. Of note, to a lesser degree, SMs were also used as enhancers of cell reprogramming in SM cocktails without TFs. Apart from cell dedifferentiation, in the last years, SMs have also been used for cell transdifferentiation (for a review see Xie et al., 2017 [13]). Still, we found among the studied SMs many that could be classified as stand-alone inducers of cell reprogramming. These SMs were able to induce cellular reprogramming by themselves, thus either fully replacing the essential TFs $[9,10]$ or by increasing their expression [35, 36]. For example, Forskolin can replace Oct4, while RepSox can substitute Sox2 (see Supplementary Table 1). Besides the classical iP by means of the combinations of overexpressed TFs (e.g., Yamanaka's factors, OSKM), a total of ten cocktails that contain SMs only with cell reprogramming activity have been established and tested thus far.

Functional analysis of SMs and their targets revealed that they are distributed between three major categories: epigenetics, intra- and inter-cellular signaling, and metabolic "switchers". All these categories appear to be mandatorily presented in each SM cocktail to induce cell reprogramming. Specifically, it seems that sufficient components for a "minimal reprogramming" cocktail have to include an inhibitor of HDAC (e.g. VPA or $\mathrm{NaB}$ ), an inhibitor of TGF $\beta$ signaling (e.g. RepSox), and GSK3-inhibiting SMs (e.g. CHIR99021 or LiCl). This assumption was further confirmed by the KEGG pathways enrichment analysis. The unusually significant enrichment of epigenetic and signaling pathways highlights their importance in chemical iP. Remarkably, many enriched pathways were related to aging, longevity and age-related diseases, thus presumably connecting them with the processes of cell reprogramming. This notion has recently been supported experimentally by demonstrating induction of cellular senescence by activation of OSKM, in vitro [37] and also in vivo on $\mathrm{i} 4 \mathrm{~F}$ reprogrammable mice [38-40]. Yet, this does not minimize the potential importance of pathways that are only slightly enriched or are not enriched at all. For example, Glycolysis/Gluconeogenesis pathway appears in our analysis as a marginally significantly enriched pathway ( $\mathrm{p}=0.051$ ), although it is a well-recognized metabolic pathway for cell reprogramming; moreover, it is well known that the pluripotent stem cells rely on glycolysis rather than OXPHOS (reviewed by [3]). The possible explanation for this result is most likely related to the small number of glycolytic enzymes among the SM targets, relative to the total number of targets. Further strengthening the importance of metabolic components of iP is the observation that the HIF-1 signaling pathway is among the most significantly enriched pathways (fold 
Table 3. SMs as human metabolites.

\begin{tabular}{|c|c|c|}
\hline Name & $\begin{array}{l}\text { Role in induced cell reprogramming } \\
\text { (inducer/enhancer) }\end{array}$ & Chemical class \\
\hline 5'-Azacytidine (5'-azaC) & Enhancer & Nucleotides and nucleotide derivatives \\
\hline 5'-Aza-2'-deoxycytidine & Enhancer & Nucleotides and nucleotide derivatives \\
\hline 7-hydroxyflavone & Enhancer & Flavonoids \\
\hline 90-D3 (Vitamin D3) & Enhancer & Steroids and steroid derivatives \\
\hline Apigenin & Enhancer & Flavonoids \\
\hline Caffeic acid & Putative enhancer or inducer & Cinnamic acids and derivatives \\
\hline Chlorogenic acid & Putative enhancer or inducer & Fatty acids and derivatives \\
\hline Curcumin & Enhancer & Diarylheptanoids \\
\hline Dasatinib & Inducer & Benzene and derivatives \\
\hline Dexamethasone & Enhancer & Steroids and steroid derivatives \\
\hline EGCG & Enhancer & Flavonoids \\
\hline Fisetin & Enhancer & Flavonoids \\
\hline Forskolin & Inducer & Benzofurans \\
\hline Fru-2,6-P2 & Enhancer & Organooxygen compounds \\
\hline Luteolin & Enhancer & Flavonoids \\
\hline $\mathrm{N}$-acetyl-cysteine & Enhancer & Amino acids and derivatives \\
\hline Sodium Butyrate (NaB) & Inducer and enhancer & Fatty acids and derivatives \\
\hline Prostaglandin $E_{2}$ & Enhancer & Fatty acids and derivatives \\
\hline Quercetin & Enhancer & Flavonoids \\
\hline Rapamycin & Enhancer & Macrolide lactams \\
\hline Resveratrol & Enhancer & Stilbenes \\
\hline Retinoic acid & Enhancer & Prenol lipids \\
\hline SAHA & Enhancer & Benzene and derivatives \\
\hline Spermidine & Enhancer & Organonitrogen compounds \\
\hline Valproic acid & Inducer & Fatty acids and derivatives \\
\hline Vitamin A (Retinol acetate) & Enhancer & Prenol lipids \\
\hline Vitamin C (Ascorbic acid; Ascorbate) & Enhancer & Dihydrofurans \\
\hline Zolpidem & Enhancer & Azoles \\
\hline
\end{tabular}

enrichment $=5, \mathrm{p}<2.0 \mathrm{E}-20)$. Indeed, the hypoxiainducible factor 1 alpha (Hif1alpha) activates glycolysis and concomitantly promotes telomerase expression and enhances self-renewal of stem cells [41]. Another important observation is that the main transcription factors of pluripotency, Oct4 and Nanog, can directly induce expression of the key glycolytic enzymes hexokinase 2 and pyruvate kinase $\mathrm{M} 2$, thus delaying differentiation and preserving pluripotency of ESCs [42].
In turn, the genes involved in the control of glucose uptake (GLUT3) and metabolism (PKM2) are also involved in the regulation of Oct 4 expression [43]. For unclear reasons, some promising SMs have not been used in reprogramming cocktails developed thus far. For example, vitamin C (see Table 3 and Supplementary Tables 1,5 ) was shown to modulate the TET enzymes, which promotes demethylation of histones and DNA, with subsequent enhancing cell reprogramming induced 
by OSKM [44-46], however it was not yet evaluated in combination with any SM cocktail.

It is still a matter of debate whether SMs act independently of each other in triggering cell reprogramming, or if they act in a cooperative, epistatic manner. The latter suggests the interactions between their targets, including direct (physical) interactions. With this in mind, we analyzed the connectivity and interconnectivity of targets of SMs and SM cocktails. The network analysis indicates that their targets are highly interconnected and form PPI networks with a scale-free topology that confers robustness and persistent connectivity. This means that: (i) the SM targets probably act in a cooperative manner to induce cell reprogramming; (ii) a scale-free topology of SM targets ensures higher integrity of the network and its resistance to random attacks $[47,48]$, thus making the cell reprogramming process highly reliable.

Recently, we hypothesized that cell reprogramming is a natural process that is triggered and regulated via two major networks - a genetic one (triggered by transcription factors, e.g. OSKM) and a chemical one (controlled by metabolites, e.g. similar to SMs) [3, 49]. In line with this hypothesis are our data demonstrating that: (i) a large number of SMs (28 of 92; Table 3) used for cell reprogramming are found in the human metabolome (derivatives of nucleotides, fatty acids, etc.), and (ii) many more metabolites (over 200) are functionally similar to SMs, thus offering the potential of being cell reprogramming agents. In addition to the chemical factors, environmental factors such as hypoxia and/or hypercapnia (which eventually act as chemical factors, namely through low concentrations of oxygen and high concentrations of carbon dioxide) may greatly influence the cell dedifferentiation process $[3,50]$. It should be mentioned again (see above) that hypoxic/hypercapnic microenvironment associated with a low reactive oxygen species (ROS) generation and activation of glycolysis, is essential for maintenance and proper functioning of dedifferentiated cells.

Further supporting our hypothesis are the data on the common targets of SM cocktails and Yamanaka's factors. This comparison revealed an insignificant overlap between the SM cocktails' targets and OSKM, except for Cocktail \#7. The lack of common targets between the cocktails and Yamanaka factors was quite a surprising observation. More prominent overlap was however observed between pathways, meaning that despite different targets, both SM cocktails and Yamanaka's factors "use" more or less the same pathways.

Altogether, this suggests that the two systems, chemical (SMs) and genetic (TFs), might cooperate to increase the efficiency of cell reprogramming. Interestingly, the overlapping pathways for SM cocktails and OSKM targets are mainly cancer- or virus-related but not related to key reprogramming processes, such as demethylation and chromatin decondensation or pluripotency pathways, as it might be expected. One of the reasons could be rooted in statistical issues. In Table 2 , only the pathways significantly overlapping with at least one SM cocktail, are presented. Another important point is that cancer-related pathways are not "purely" cancer pathways, but include many components related to cell division and reprogramming. For example, Wnt $/ \beta$-catenin and MAPK signaling pathways are known for their role in cell dedifferentiation [51, 52]. These pathways are also well known for their involvement in carcinogenesis [53].

Although beyond the scope of the present study, it is worth mentioning that there is a significant overlap between the collected $92 \mathrm{SMs}$ and the compounds found in the DrugAge database [54] $(n=20$ drugs; $p=4.95 E-$ 15). Among the common drugs are Rapamycin, Valproic acid, Caffeic acid, and Lithium chloride. Similarly, there is a large overlap between the SM targets and the longevity-associated genes (LAGs) hosted in the GenAge database [55] $(n=132, p=3 E-88$ for human LAGs and $n$ $=136, \mathrm{p}=5 \mathrm{E}-24$ for human orthologs of model organism LAGs). Lastly, SM targets also overlap with the list of genes related to cellular senescence (CS) from the CellAge database [2] $(n=85, p=1 E-42)$. As a point for further investigation is testing the established or newly constructed SM cocktails in vivo. In this regard, testing SM cocktails in the naked mole-rat model could be of particular interest as induction of pluripotency in the cells of this animal requires special conditions and is not always achievable [56-58].

All in all, SMs and their relationship with TFs definitely warrants further investigation which could probably shed more light on the mechanisms of cell reprogramming and will be helpful for developing the most optimal SM cocktails with effects on CS, aging and longevity.

\section{MATERIALS AND METHODS}

\section{Data sources}

Data on SMs for cell reprogramming were gathered from publicly available literature, using PubMed NCBI (http://www.ncbi.nlm.nih.gov/pubmed/) and Google Scholar (https://scholar.google.com/). Additional data about the chemical and biological properties of SMs were obtained from PubChem [59], https://pubchem. ncbi.nlm.nih.gov/ and from the Human Metabolome Database (HMDB) [24], http://www.hmdb.ca/. Briefly, 
HMDB contains the collection of small molecules found in the human body, including nucleic acids, carbohydrates, lipids, peptides, amino acids, organic acids, biogenic amines, vitamins, minerals, food additives, drugs, cosmetics, contaminants, pollutants, and other chemicals that enter the human body [24].

\section{Data mining and organization}

The papers were searched using the following keywords: "induced pluripotency", "chemically induced pluripotency", "chemical reprogramming", "chemically induced dedifferentiation", "induction of pluripotency by small molecules". In order to be included in the analysis, each article had to contain data: (i) on $\mathrm{SM}(\mathrm{s})$ or their cocktail(s) that either induced or enhanced cellular reprogramming; (ii) on the bioactivity of the SMs; and (iii) on the SM dosage and cell type. According to their role in cell reprogramming, the compounds found were divided into two major groups of molecules: iP inducers and iP enhancers. Since it was not always possible to definitely link the compounds to one of the groups, as in some cases a given compound was considered an inducer and in other cases an enhancer, these entities were marked as "inducer and/or enhancer". From each paper the following data were collected and manually curated: (i) the name(s) of $\mathrm{SM}(\mathrm{s})$ that either induce or enhance pluripotency, with or without TFs; (ii) the effect of SM(s) on the iP efficiency; and (iii) whether a given SM can substitute the pluripotency-associated TFs. The collected SMs were organized in a table as shown in Supplementary Tables 1, 6 . The data regarding each compound included: common name, formula, molecular weight (MW), main bioactivity/target(s), comments relevant to cellular reprogramming, link to PubChem references, PMID. Only the SM cocktails which induced cell reprogramming (not necessary to the stage of iPSCs) without TFs were included in the analysis.

\section{Drug-protein interaction network}

To determine the protein targets of the collected SMs, we used the STITCH database (version 5.0), http://stitch.embl.de/, one of the largest repositories of chemical-protein interactions [27], which include direct (physical) and indirect (functional) interactions. For the scope of the analyses in this study, text-mining and predicted interactions were excluded. If not indicated otherwise, a confidence score of medium stringency (0.4) was used for including interaction in the analysis. Drug similarity analysis was performed using the STITCH tool as described by Kuhn et al. [60].

\section{Gene targets overlap}

To obtain the list of OSKM transcription factors the TRRUST database [61], https://www.grnpedia.org/tr rust/, was used. The overlaps between gene targets of drug cocktails and OSKM transcription factors were calculated using only the genes that are present in both STITCH and TRRUST databases. In order to compute the overlap between gene targets of SMs and GenAge [55], https://genomics.senescence.info/genes/index.html, two lists of longevity-associated genes (LAGs) were used: i) the manually curated list of human LAGs from GenAge, build 20 and ii) the human orthologs of model organisms LAGs from GenAge, build 20. Orthologs of genes were computed using a script developed in our lab, that queries the database InParanoid 8 [62], https://in paranoid.sbc.su.se/cgi-bin/index.cgi. For stringency, we selected for each gene only inparalogs with scores of 1.0. The significance of the overlaps with GenAge [55] and CellAge [2] - https://genomics.senescence.info/cells/, was computed using Fisher's exact test.

\section{SMs overlap with chemical databases}

The overlaps between: i) the list of SMs and HMDB, and ii) the list of SMs and DrugAge [54] were calculated using the PubChem IDs of the compounds as identifiers. The significance of the overlap was computed using Fisher's exact test and considering all PubChem and all DrugBank compounds, respectively, as background.

\section{KEGG pathways and gene ontology enrichment analysis}

Functional and pathway enrichment analyses were performed with the DAVID Bioinformatics Resources tool, version 6.8 [22], https://david.ncifcrf.gov. Statistical significance of enrichment was evaluated using default parameters set in DAVID. A threshold of 0.001 was used for the adjusted $P$-value.

\section{Protein-protein interaction networks}

Protein-protein interaction (PPI) data were taken from the BioGRID database [23], http://thebiogrid.org, human interactome, Build 3.5.177. The PPI network construction and analyses were performed using Cytoscape [63], http://www.cytoscape.org, version 3.7.1. Prior to any network analyses, genetic interactions, self-loops, duplicate edges and interactions with proteins from other species were removed from the interactome, and the remaining network was used as a control. The interconnectivity was computed as the fraction of nodes in the largest connected component out of the input gene set, by using the breadth-first 
search algorithm. Modeling the relationship between node subset size and interconnectivity in the human interactome was carried out by randomly sampling subsets of nodes in the interactome, with a sample size varying from 50 to 17,600 nodes (step of 50). In this case, sampling was performed 100 times for each subset size. In order to evaluate the statistical significance of the observed network interconnectivity for cocktails and SMs gene targets, random sampling from the BioGRID network was performed 1000 times, for a subset of nodes of equal size to each evaluated network. For each set of random samplings, average interconnectivity, standard deviation and $\mathrm{z}$-score of the observed interconnectivity were computed.

For a joint protein-drug network, the protein targets of the collected SMs, determined from the STITCH database, were used together with PPIs from BioGRID.

\section{Abbreviations}

2-Me-5HT: 2-methyl-5-hydroxytryptamine; 8-Br-cAMP: Bromoadenosine 3', 5'-cyclic monophosphate; BrdU: Bromodeoxyuridine; CS: Cellular senescence; D2-5HT2A: Dopamine D2 and serotonin 5-HT2A receptors; DARPP-32: Dopamine- and cAMP-regulated phosphoprotein; DNMT: DNA methyltransferase; DZNep: 3-Deazaneplanocin A; EGCG: Epigallocatechin3-Gallate; ESCs: Embryonic stem cells; EZH: Enhancer of Zeste Homologue; Fru-2,6-P2: Fructose 2,6bisphosphate; GSK3: Glycogen synthase kinase 3; HDAC: Histone deacetylase; HIF: Hypoxia-inducible factor-1; Hiflalpha: Hypoxia-inducible factor 1 alpha; HMDB: Human Metabolome Database; HMT: Histone methyltransferase; IBMX: 3-Isobutyl-1-Methylxanthine; iP: Induced pluripotency; LAGs: Longevity-associated genes; MW: Molecular weight; O4I3: OCT4-inducing compound 3; OSKM: Oct3/4, Sox2, Klf4, and c-Myc (Yamanaka's factors); PDK1: 3'-phosphoinositidedependent kinase-1; PFK-1: Phosphofructokinase 1; PI3K: Phosphoinositide 3-kinase; PPIs: Protein-protein interactions; ROS: Reactive oxygen species; SAH: S-Adenosyl-l-homocysteine; SAHA: Suberoylanilide hydroxamic acid; SMs: Small molecules; TFs: Transcription factors.

\section{Abbreviations for SM cocktails}

\section{Cocktail 1 (VC6TF + TTNPB + DZNep)}

Valproic acid (V, VPA)

CHIR99021 (C)

RepSox (6)

Parnate (T)

Forskolin (F)

DZNep
TTNPB

Cocktail 2 (NLS)

$\mathrm{NaB}$

$\mathrm{LiCl}$

SB431542

\section{Cocktail 3 (VCR)}

Valproic acid

CHIR99021

RepSox

Cocktail 4 (TLT)

Trichostatin A (TSA)

$\mathrm{Li} 2 \mathrm{CO} 3$

Tranilast

Cocktail 5 (BrdUC6F)

BrdU

CHIR99021

RepSox

Forskolin

Cocktail $6($ VC6TF + AM 580 + EPZ004777)

VPA

CHIR99021

RepSox

Parnate

Forskolin

AM 580

EPZ004777

Cocktail 7 (VC6TF + AM580 + DZNep + 5-aza-dC + SGC0946 + EPZ004777) SMs and their protein targets.

VPA

CHIR99021

RepSox

Parnate

Forskolin

AM 580

DZNep

5-aza-dC

SGC0946

EPZ004777

Cocktail 8 (VC6TF + DZNep)

VPA

CHIR99021 
RepSOX

Parnate

Forskolin

DZNep

\section{Cocktail 9 (VC6TF + AM 580 + DZNep)}

VPA

CHIR99021

RepSox

Parnate

Forskolin

AM 580

DZNep

\section{Cocktail 10 (CNaATP)}

CHIR99021

$\mathrm{NaB}$

cyclic pifithrin-a (a)

A-83-01

Thiazovivin

PD0325901

\section{AUTHOR CONTRIBUTIONS}

This study was carried out by the VEF and RT research groups. Data collection, processing, analysis of the result and their description were done by $\mathrm{AK}$ and GB. Interpretation of the results was done by all authors. VEF and RT coordinated and supervised the project. All authors have participated in the writing of the manuscript. All authors reviewed the manuscript.

\section{CONFLICTS OF INTEREST}

The authors declare that they have no conflicts of interest.

\section{FUNDING}

This work was supported by the National Authority for Scientific Research and Innovation, and by the Ministry of European Funds, Romania, through the Competitiveness Operational Programme 2014-2020, POC-A.1-A.1.1.4-E-2015 [Grant number: 40/02.09.2016, ID: P_37_778, to RT] and by the Romanian Ministry of Education and Research, CCCDI - UEFISCDI, through PNCDI III [Grant number: PN-III-P2-2.1-PED-20192593 to RT]. We are also grateful for the funding received from the Dr. Amir Abramovich Research Fund [granted to VEF].

\section{REFERENCES}

1. Moskalev AA, Shaposhnikov MV, Plyusnina EN, Zhavoronkov A, Budovsky A, Yanai H, Fraifeld VE. The role of DNA damage and repair in aging through the prism of Koch-like criteria. Ageing Res Rev. 2013; 12:661-84.

https://doi.org/10.1016/j.arr.2012.02.001

PMID:22353384

2. Avelar RA, Ortega JG, Tacutu R, Tyler EJ, Bennett D, Binetti P, Budovsky A, Chatsirisupachai K, Johnson E, Murray A, Shields S, Tejada-Martinez D, Thornton D, et al. A multidimensional systems biology analysis of cellular senescence in aging and disease. Genome Biol. 2020; 21:91. https://doi.org/10.1186/s13059-020-01990-9 PMID:32264951

3. Muradian KK, Fraifeld VE. iPSCs-Induced Cellular Reprogramming. Encyclopedia of Biomedical Gerontology. Academic Press. 2020; 291-8. https://doi.org/10.1016/B978-0-12-801238-3.11299-1

4. Takahashi K, Yamanaka S. Induction of pluripotent stem cells from mouse embryonic and adult fibroblast cultures by defined factors. Cell. 2006; 126:663-76. https://doi.org/10.1016/i.cell.2006.07.024 PMID:16904174

5. Takahashi K, Tanabe K, Ohnuki M, Narita M, Ichisaka T, Tomoda K, Yamanaka S. Induction of pluripotent stem cells from adult human fibroblasts by defined factors. Cell. 2007; 131:861-72.

https://doi.org/10.1016/j.cell.2007.11.019

PMID: 18035408

6. Buganim $Y$, Markoulaki S, van Wietmarschen N, Hoke H, Wu T, Ganz K, Akhtar-Zaidi B, He Y, Abraham BJ, Porubsky D, Kulenkampff E, Faddah DA, Shi L, et al. The developmental potential of iPSCs is greatly influenced by reprogramming factor selection. Cell Stem Cell. 2014; 15:295-309.

https://doi.org/10.1016/i.stem.2014.07.003

PMID:25192464

7. Yu J, Vodyanik MA, Smuga-Otto K, Antosiewicz-Bourget J, Frane JL, Tian S, Nie J, Jonsdottir GA, Ruotti V, Stewart R, Slukvin II, Thomson JA. Induced pluripotent stem cell lines derived from human somatic cells. Science. 2007; 318:1917-20. https://doi.org/10.1126/science.1151526 PMID:18029452

8. Liao J, Wu Z, Wang Y, Cheng L, Cui C, Gao Y, Chen T, Rao L, Chen S, Jia N, Dai H, Xin S, Kang J, et al. Enhanced efficiency of generating induced pluripotent stem (iPS) cells from human somatic cells by a combination of six transcription factors. Cell Res. 2008; 18:600-3. https://doi.org/10.1038/cr.2008.51 PMID: 18414447

9. Hou P, Li Y, Zhang X, Liu C, Guan J, Li H, Zhao T, Ye J, 
Yang W, Liu K, Ge J, Xu J, Zhang Q, et al. Pluripotent stem cells induced from mouse somatic cells by smallmolecule compounds. Science. 2013; 341:651-4.

https://doi.org/10.1126/science.1239278

PMID:23868920

10. Cheng L, Hu W, Qiu B, Zhao J, Yu Y, Guan W, Wang M, Yang W, Pei G. Generation of neural progenitor cells by chemical cocktails and hypoxia. Cell Res. 2014; 24:665-79.

https://doi.org/10.1038/cr.2014.32 PMID:24638034

11. Ye J, Ge J, Zhang X, Cheng L, Zhang Z, He S, Wang Y, Lin $\mathrm{H}$, Yang W, Liu J, Zhao $\mathrm{Y}$, Deng $\mathrm{H}$. Pluripotent stem cells induced from mouse neural stem cells and small intestinal epithelial cells by small molecule compounds. Cell Res. 2016; 26:34-45.

https://doi.org/10.1038/cr.2015.142 PMID:26704449

12. Anwar MA, Kim S, Choi S. The triumph of chemically enhanced cellular reprogramming: a patent review. Expert Opin Ther Pat. 2016; 26:265-80. https://doi.org/10.1517/13543776.2016.1118058 PMID:26593376

13. Xie X, Fu Y, Liu J. Chemical reprogramming and transdifferentiation. Curr Opin Genet Dev. 2017; 46:104-13.

https://doi.org/10.1016/j.gde.2017.07.003

PMID:28755566

14. Huang C, Tu W, Fu Y, Wang J, Xie X. Chemical-induced cardiac reprogramming in vivo. Cell Res. 2018; 28:686-9.

https://doi.org/10.1038/s41422-018-0036-4

PMID:29670223

15. Skoda AM, Simovic D, Karin V, Kardum V, Vranic S, Serman L. The role of the Hedgehog signaling pathway in cancer: A comprehensive review. Bosn J Basic Med Sci. 2018; 18:8-20.

https://doi.org/10.17305/bjbms.2018.2756

PMID:29274272

16. Sánchez-de-Diego C, Valer JA, Pimenta-Lopes C, Rosa $\mathrm{JL}$, Ventura F. Interplay between BMPs and Reactive Oxygen Species in Cell Signaling and Pathology. Biomolecules. 2019; 9:534.

https://doi.org/10.3390/biom9100534

PMID:31561501

17. Taylor A, Rudd CE. Small Molecule Inhibition of Glycogen Synthase Kinase-3 in Cancer Immunotherapy. Adv Exp Med Biol. 2019; 1164:225-33.

https://doi.org/10.1007/978-3-030-22254-3 17

PMID: $\underline{1576552}$

18. Zhao Y, Zhao T, Guan J, Zhang X, Fu Y, Ye J, Zhu J, Meng G, Ge J, Yang S, Cheng L, Du Y, Zhao C, et al. A XEN-like State Bridges Somatic Cells to Pluripotency during
Chemical Reprogramming. Cell. 2015; 163:1678-91.

https://doi.org/10.1016/i.cell.2015.11.017

PMID:26686652

19. Ichida JK, Blanchard J, Lam K, Son EY, Chung JE, Egli D, Loh KM, Carter AC, Di Giorgio FP, Koszka K, Huangfu D, Akutsu $\mathrm{H}$, Liu DR, et al. A small-molecule inhibitor of Tgf-Beta signaling replaces sox 2 in reprogramming by inducing nanog. Cell Stem Cell. 2009; 5:491-503.

https://doi.org/10.1016/i.stem.2009.09.012 PMID:19818703

20. Li D, Wang L, Hou J, Shen Q, Chen Q, Wang X, Du J, Cai $X$, Shan $Y$, Zhang T, Zhou T, Shi X, Li Y, et al. Optimized Approaches for Generation of Integration-free iPSCs from Human Urine-Derived Cells with Small Molecules and Autologous Feeder. Stem Cell Reports. 2016; 6:717-28.

https://doi.org/10.1016/i.stemcr.2016.04.001 PMID:27132887

21. Long $\mathrm{Y}$, Wang $\mathrm{M}, \mathrm{Gu} \mathrm{H}$, Xie X. Bromodeoxyuridine promotes full-chemical induction of mouse pluripotent stem cells. Cell Res. 2015; 25:1171-4. https://doi.org/10.1038/cr.2015.96 PMID:26251165

22. Huang DW, Sherman BT, Lempicki RA. Systematic and integrative analysis of large gene lists using DAVID bioinformatics resources. Nat Protoc. 2009; 4:44-57.

https://doi.org/10.1038/nprot.2008.211 PMID:19131956

23. Oughtred R, Stark C, Breitkreutz BJ, Rust J, Boucher L, Chang C, Kolas N, O'Donnell L, Leung G, McAdam R, Zhang F, Dolma S, Willems A, et al. The BioGRID interaction database: 2019 update. Nucleic Acids Res. 2019; 47:D529-41.

https://doi.org/10.1093/nar/gky1079

PMID: 30476227

24. Wishart DS, Feunang YD, Marcu A, Guo AC, Liang K, Vázquez-Fresno R, Sajed T, Johnson D, Li C, Karu N, Sayeeda Z, Lo E, Assempour N, et al. HMDB 4.0: the human metabolome database for 2018. Nucleic Acids Res. 2018; 46:D608-17. https://doi.org/10.1093/nar/gkx1089 PMID:29140435

25. Musillo C, Borgi M, Saul N, Möller S, Luyten W, Berry A, Cirulli F. Natural products improve healthspan in aged mice and rats: A systematic review and meta-analysis. Neurosci Biobehav Rev. 2021; 121:89-105. https://doi.org/10.1016/j.neubiorev.2020.12.001 PMID:33309907

26. Ghodke-Puranik Y, Thorn CF, Lamba JK, Leeder JS, Song W, Birnbaum AK, Altman RB, Klein TE. Valproic acid pathway: pharmacokinetics and pharmacodynamics. Pharmacogenet Genomics. 2013; 23:236-41. https://doi.org/10.1097/FPC.0b013e32835ea0b2 
PMID:23407051

27. Szklarczyk D, Santos A, von Mering C, Jensen L, Bork P, Kuhn M. STITCH 5: augmenting protein-chemical interaction networks with tissue and affinity data. Nucleic Acids Res. 2016; 44:D380-4. https://doi.org/10.1093/nar/gkv1277 PMID:26590256

28. Xie M, Cao N, Ding S. Small molecules for cell reprogramming and heart repair: progress and perspective. ACS Chem Biol. 2014; 9:34-44.

https://doi.org/10.1021/cb400865w

PMID:24372513

29. Baranek M, Markiewicz WT, Barciszewski J. Selected small molecules as inducers of pluripotency. Acta Biochim Pol. 2016; 63:709-16. https://doi.org/10.18388/abp.2016 1363 PMID:27785481

30. Qin H, Zhao A, Fu X. Small molecules for reprogramming and transdifferentiation. Cell Mol Life Sci. 2017; 74:3553-75.

https://doi.org/10.1007/s00018-017-2586-x

PMID:28698932

31. Qin H, Zhao A, Fu X. Chemical modulation of cell fates: in situ regeneration. Sci China Life Sci. 2018; 61:1137-50.

https://doi.org/10.1007/s11427-018-9349-5

PMID:30099708

32. Kim Y, Jeong J, Choi D. Small-molecule-mediated reprogramming: a silver lining for regenerative medicine. Exp Mol Med. 2020; 52:213-26.

https://doi.org/10.1038/s12276-020-0383-3

PMID:32080339

33. Federation AJ, Bradner JE, Meissner A. The use of small molecules in somatic-cell reprogramming. Trends Cell Biol. 2014; 24:179-87. https://doi.org/10.1016/j.tcb.2013.09.011 PMID:24183602

34. Baranek $M$, Belter A, Naskręt-Barciszewska MZ, Stobiecki M, Markiewicz WT, Barciszewski J. Effect of small molecules on cell reprogramming. Mol Biosyst. 2017; 13:277-313.

https://doi.org/10.1039/c6mb00595k

PMID:27918060

35. Li Y, Zhang $Q$, Yin X, Yang W, Du Y, Hou P, Ge J, Liu C, Zhang W, Zhang X, Wu Y, Li H, Liu K, et al. Generation of iPSCs from mouse fibroblasts with a single gene, Oct4, and small molecules. Cell Res. 2011; 21:196-204. https://doi.org/10.1038/cr.2010.142 PMID:20956998

36. Wei X, Chen Y, Xu Y, Zhan Y, Zhang R, Wang M, Hua Q, $\mathrm{Gu} H$, Nan F, Xie X. Small molecule compound induces chromatin de-condensation and facilitates induced pluripotent stem cell generation. J Mol Cell Biol. 2014; 6:409-20.

https://doi.org/10.1093/jmcb/mju024

PMID:24838272

37. Banito A, Rashid ST, Acosta JC, Li S, Pereira CF, Geti I, Pinho S, Silva JC, Azuara V, Walsh M, Vallier L, Gil J. Senescence impairs successful reprogramming to pluripotent stem cells. Genes Dev. 2009; 23:2134-9.

https://doi.org/10.1101/gad.1811609 PMID:19696146

38. Mosteiro L, Pantoja C, Alcazar N, Marión RM, Chondronasiou D, Rovira M, Fernandez-Marcos PJ, Muñoz-Martin M, Blanco-Aparicio C, Pastor J, GómezLópez G, De Martino A, Blasco MA, et al. Tissue damage and senescence provide critical signals for cellular reprogramming in vivo. Science. 2016; 354:aaf4445.

https://doi.org/10.1126/science.aaf4445 PMID:27884981

39. Mosteiro L, Pantoja C, de Martino A, Serrano M. Senescence promotes in vivo reprogramming through p16 INK4a and IL-6. Aging Cell. 2018; 17:e12711.

https://doi.org/10.1111/acel.12711

PMID:29280266

40. Ritschka B, Storer M, Mas A, Heinzmann F, Ortells MC, Morton JP, Sansom OJ, Zender L, Keyes WM. The senescence-associated secretory phenotype induces cellular plasticity and tissue regeneration. Genes Dev. 2017; 31:172-83.

https://doi.org/10.1101/gad.290635.116

PMID:28143833

41. Mathews J, Davy PM, Gardner LH, Allsopp RC. Stem cells, telomerase regulation and the hypoxic state. Front Biosci (Landmark Ed). 2016; 21:303-15.

https://doi.org/10.2741/4389

PMID:26709774

42. Kim $H$, Jang $H$, Kim TW, Kang BH, Lee SE, Jeon YK, Chung DH, Choi J, Shin J, Cho EJ, Youn HD. Core Pluripotency Factors Directly Regulate Metabolism in Embryonic Stem Cell to Maintain Pluripotency. Stem Cells. 2015; 33:2699-711.

https://doi.org/10.1002/stem.2073

PMID:26059508

43. Christensen DR, Calder PC, Houghton FD. GLUT3 and PKM2 regulate OCT4 expression and support the hypoxic culture of human embryonic stem cells. Sci Rep. 2015; 5:17500.

https://doi.org/10.1038/srep17500 PMID:26639784

44. Esteban MA, Wang T, Qin B, Yang J, Qin D, Cai J, Li W, Weng Z, Chen J, Ni S, Chen K, Li Y, Liu X, et al. Vitamin C enhances the generation of mouse and human induced 
pluripotent stem cells. Cell Stem Cell. 2010; 6:71-9. https://doi.org/10.1016/i.stem.2009.12.001 PMID:20036631

45. Chen J, Guo L, Zhang L, Wu H, Yang J, Liu H, Wang X, Hu X, Gu T, Zhou Z, Liu J, Liu J, Wu H, et al. Vitamin C modulates TET1 function during somatic cell reprogramming. Nat Genet. 2013; 45:1504-9.

https://doi.org/10.1038/ng.2807

PMID:24162740

46. Lee Chong T, Ahearn EL, Cimmino L. Reprogramming the Epigenome With Vitamin C. Front Cell Dev Biol. 2019; 7:128.

https://doi.org/10.3389/fcell.2019.00128

PMID:31380368

47. Barabási AL, Oltvai ZN. Network biology: understanding the cell's functional organization. Nat Rev Genet. 2004; 5:101-13.

https://doi.org/10.1038/nrg1272

PMID:14735121

48. Tacutu R, Budovsky A, Wolfson M, Fraifeld VE. MicroRNA-regulated protein-protein interaction networks: how could they help in searching for prolongevity targets? Rejuvenation Res. 2010; 13:373-7. https://doi.org/10.1089/rej.2009.0980 PMID:20367577

49. Muradian KK, Tolstun DA, Paier AG, Popa-Wagner A, Fraifeld VE. Embryonic Stem Cells, Telomeres and Aging. J Ageing Restor Med. 2019; 2:115-22.

50. Tolstun DA, Knyazer A, Tushynska TV, Dubiley TA, Bezrukov VV, Fraifeld VE, Muradian KK. Metabolic remodelling of mice by hypoxic-hypercapnic environment: imitating the naked mole-rat. Biogerontology. 2020; 21:143-53. https://doi.org/10.1007/s10522-019-09848-9 PMID:31667660

51. Zhang C, Chen P, Fei Y, Liu B, Ma K, Fu X, Zhao Z, Sun T, Sheng $Z$. Wnt/ $\beta$-catenin signaling is critical for dedifferentiation of aged epidermal cells in vivo and in vitro. Aging Cell. 2012; 11:14-23.

https://doi.org/10.1111/j.1474-9726.2011.00753.x

PMID:21967252

52. Cai SA, Fu X, Sheng Z. Dedifferentiation: A New Approach in Stem Cell Research. Bioscience. 2007; 57:655.

https://doi.org/10.1641/B570805

53. Ring A, Kim YM, Kahn M. Wnt/catenin signaling in adult stem cell physiology and disease. Stem Cell Rev Rep. 2014; 10:512-25. https://doi.org/10.1007/s12015-014-9515-2 PMID:24825509

54. Barardo D, Thornton D, Thoppil H, Walsh M, Sharifi S,
Ferreira S, Anžič A, Fernandes M, Monteiro P, Grum T, Cordeiro R, De-Souza EA, Budovsky A, et al. The DrugAge database of aging-related drugs. Aging Cell. 2017; 16:594-7. https://doi.org/10.1111/acel.12585 PMID:28299908

55. Tacutu R, Thornton D, Johnson E, Budovsky A, Barardo D, Craig T, Diana E, Lehmann G, Toren D, Wang J, Fraifeld VE, de Magalhães JP. Human Ageing Genomic Resources: new and updated databases. Nucleic Acids Res. 2018; 46:D1083-90.

https://doi.org/10.1093/nar/gkx1042 PMID:29121237

56. Lee SG, Mikhalchenko AE, Yim SH, Lobanov AV, Park JK, Choi KH, Bronson RT, Lee CK, Park TJ, Gladyshev VN. Naked Mole Rat Induced Pluripotent Stem Cells and Their Contribution to Interspecific Chimera. Stem Cell Reports. 2017; 9:1706-20.

https://doi.org/10.1016/i.stemcr.2017.09.013 PMID:29107591

57. Lee SG, Mikhalchenko AE, Yim SH, Gladyshev VN. A naked mole rat iPSC line expressing drug-inducible mouse pluripotency factors developed from embryonic fibroblasts. Stem Cell Res. 2018; 31:197-200.

https://doi.org/10.1016/j.scr.2018.06.010 PMID:30107334

58. Tan L, Ke Z, Tombline G, Macoretta N, Hayes K, Tian X, Lv R, Ablaeva J, Gilbert M, Bhanu NV, Yuan ZF, Garcia BA, Shi YG, et al. Naked Mole Rat Cells Have a Stable Epigenome that Resists iPSC Reprogramming. Stem Cell Reports. 2017; 9:1721-34.

https://doi.org/10.1016/j.stemcr.2017.10.001 PMID:29107597

59. Kim S, Chen J, Cheng T, Gindulyte A, He J, He S, Li Q, Shoemaker BA, Thiessen PA, Yu B, Zaslavsky L, Zhang J, Bolton EE. PubChem 2019 update: improved access to chemical data. Nucleic Acids Res. 2019; 47:D1102-9. https://doi.org/10.1093/nar/gky1033 PMID:30371825

60. Kuhn M, Szklarczyk D, Pletscher-Frankild S, Blicher TH, von Mering $C$, Jensen $\amalg$, Bork P. STITCH 4: integration of protein-chemical interactions with user data. Nucleic Acids Res. 2014; 42:D401-7. https://doi.org/10.1093/nar/gkt1207 PMID:24293645

61. Han H, Cho JW, Lee S, Yun A, Kim H, Bae D, Yang S, Kim $C Y$, Lee $M$, Kim E, Lee S, Kang B, Jeong D, et al. TRRUST V2: an expanded reference database of human and mouse transcriptional regulatory interactions. Nucleic Acids Res. 2018; 46:D380-6.

https://doi.org/10.1093/nar/gkx1013 PMID:29087512

62. Sonnhammer EL, Östlund G. InParanoid 8: orthology analysis between 273 proteomes, mostly eukaryotic. Nucleic Acids Res. 2015; 43:D234-9. https://doi.org/10.1093/nar/gku1203 
PMID:25429972

63. Shannon P, Markiel A, Ozier O, Baliga NS, Wang JT, Ramage D, Amin N, Schwikowski B, Ideker T. Cytoscape: a software environment for integrated models of biomolecular interaction networks. Genome Res. 2003; 13:2498-504.

https://doi.org/10.1101/gr.1239303

PMID:14597658 


\section{SUPPLEMENTARY MATERIALS}

\section{Supplementary Figures}

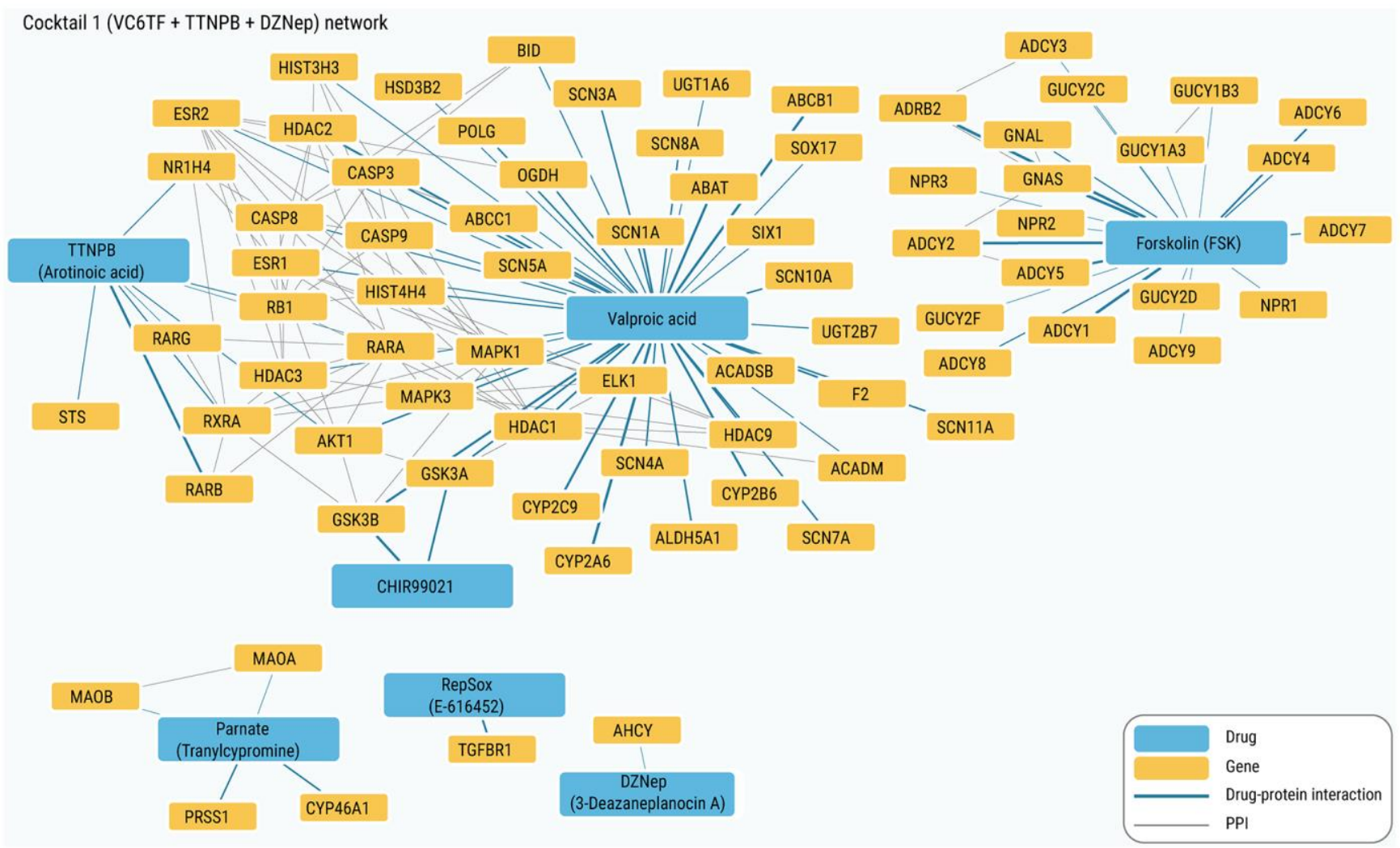

Supplementary Figure 1. The network of cocktail 1 (VC6TF + TTNPB + DZNep) SMs and their protein targets.

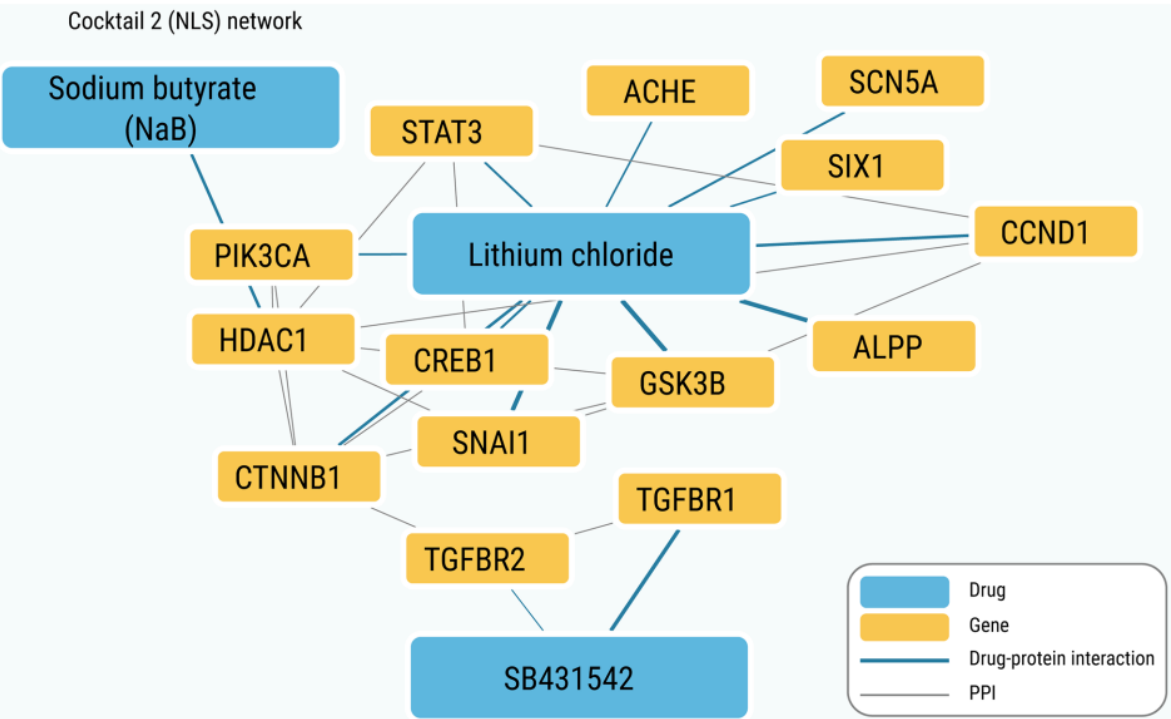

Supplementary Figure 2. The network of cocktail 2 (NLS) SMs and their protein targets. 


\section{Cocktail 3 (VCR) network}

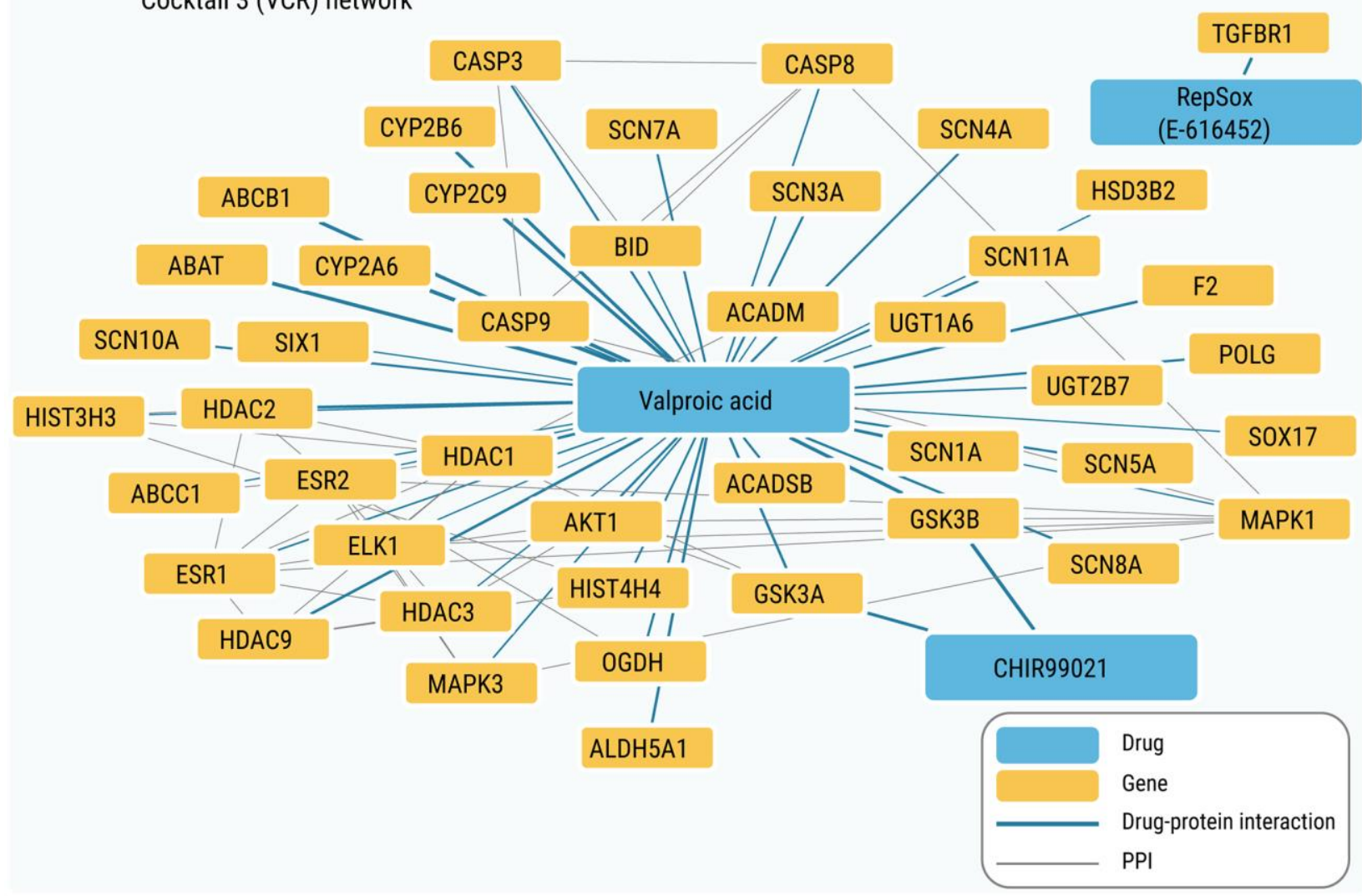

Supplementary Figure 3. The network of cocktail 3 (VCR) SMs and their protein targets.

The network of Cocktail 5 (BrdUC6F)

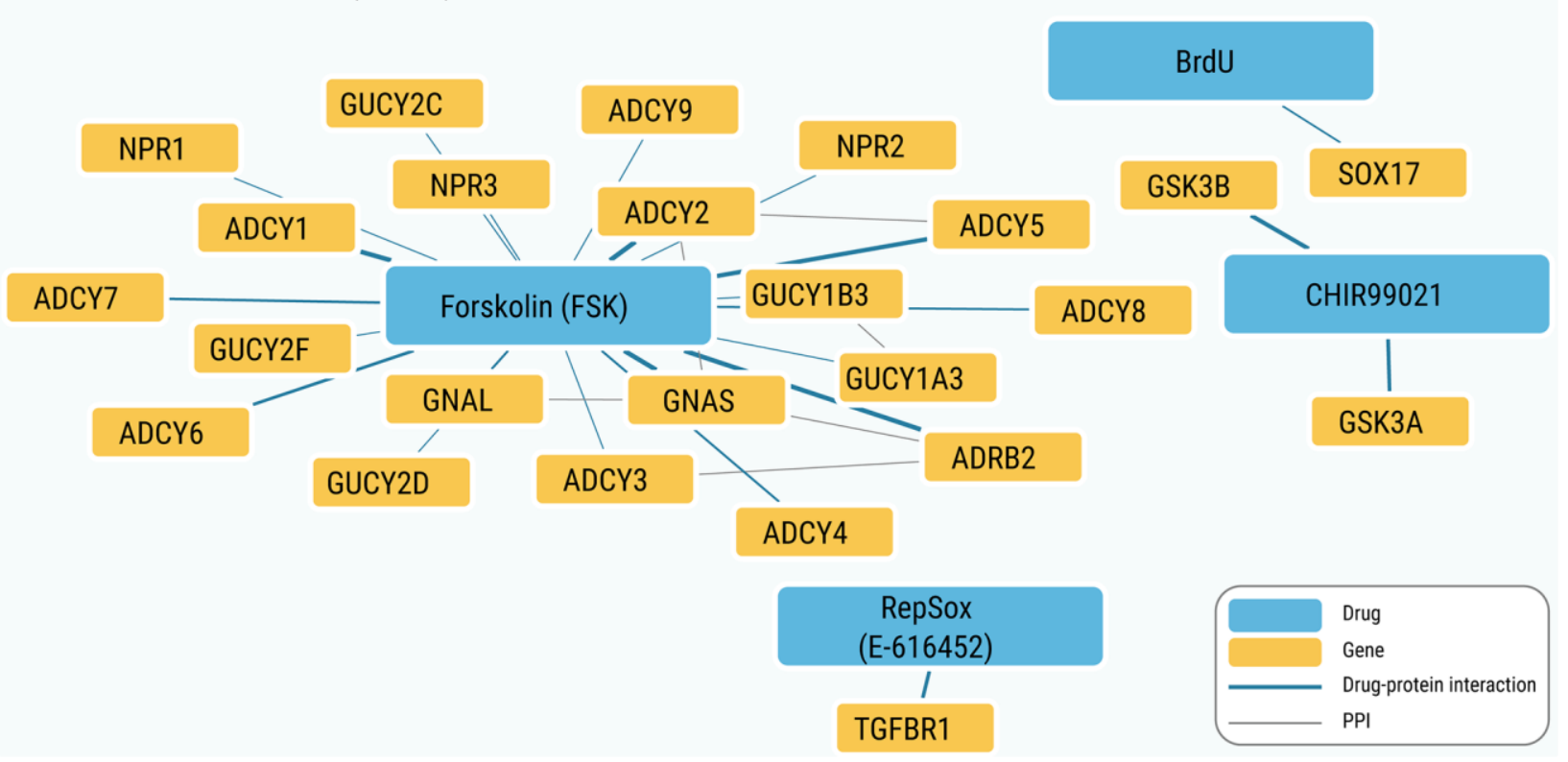

Supplementary Figure 4. The network of cocktail 5 (BrdUC6F) SMs and their protein targets. 
The network of Cocktail 6 (VC6TF + AM 580 + EPZ004777)

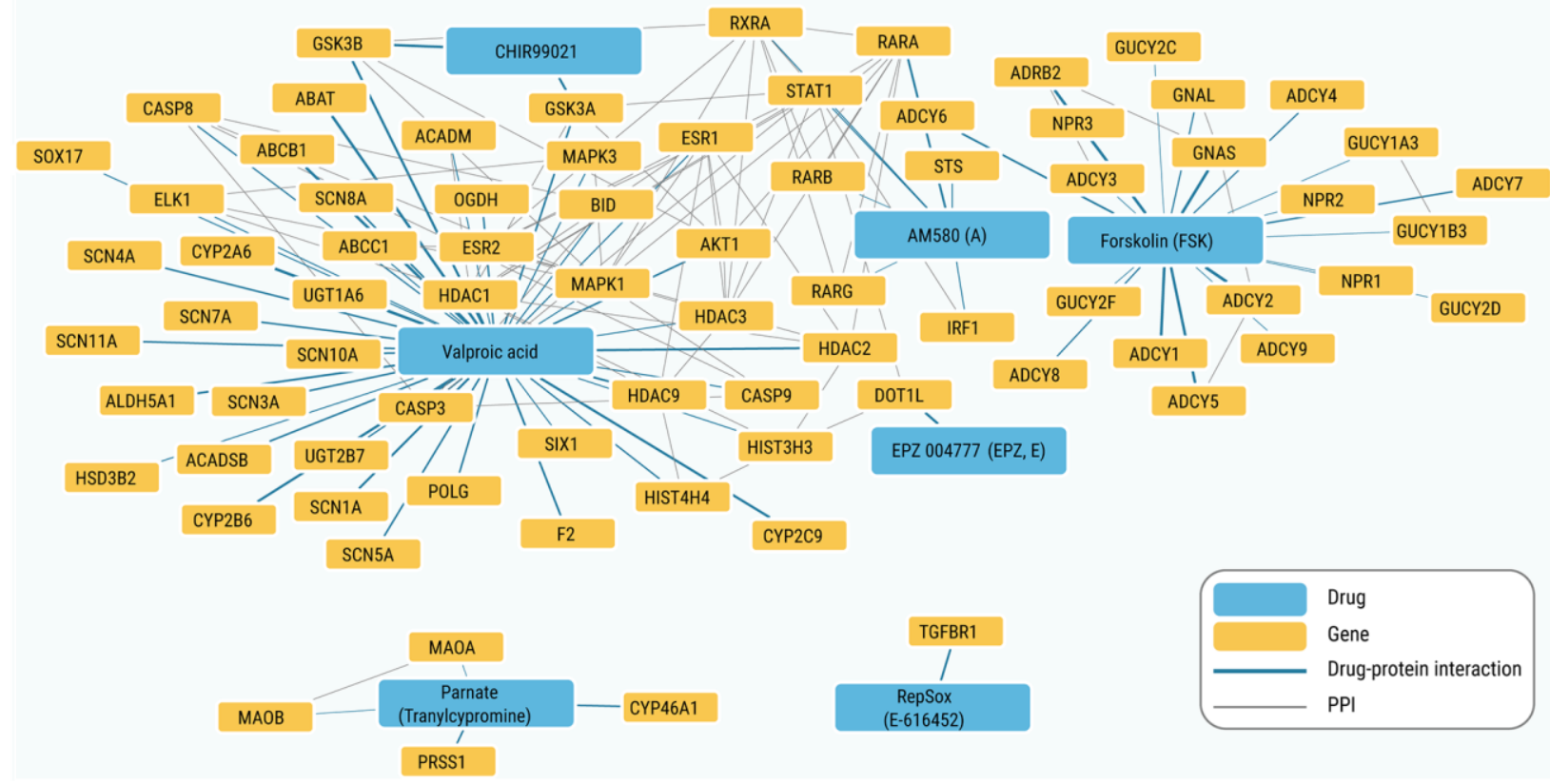

Supplementary Figure 5. The network of cocktail 6 (VC6TF + AM 580 + EPZ004777) SMs and their protein targets.

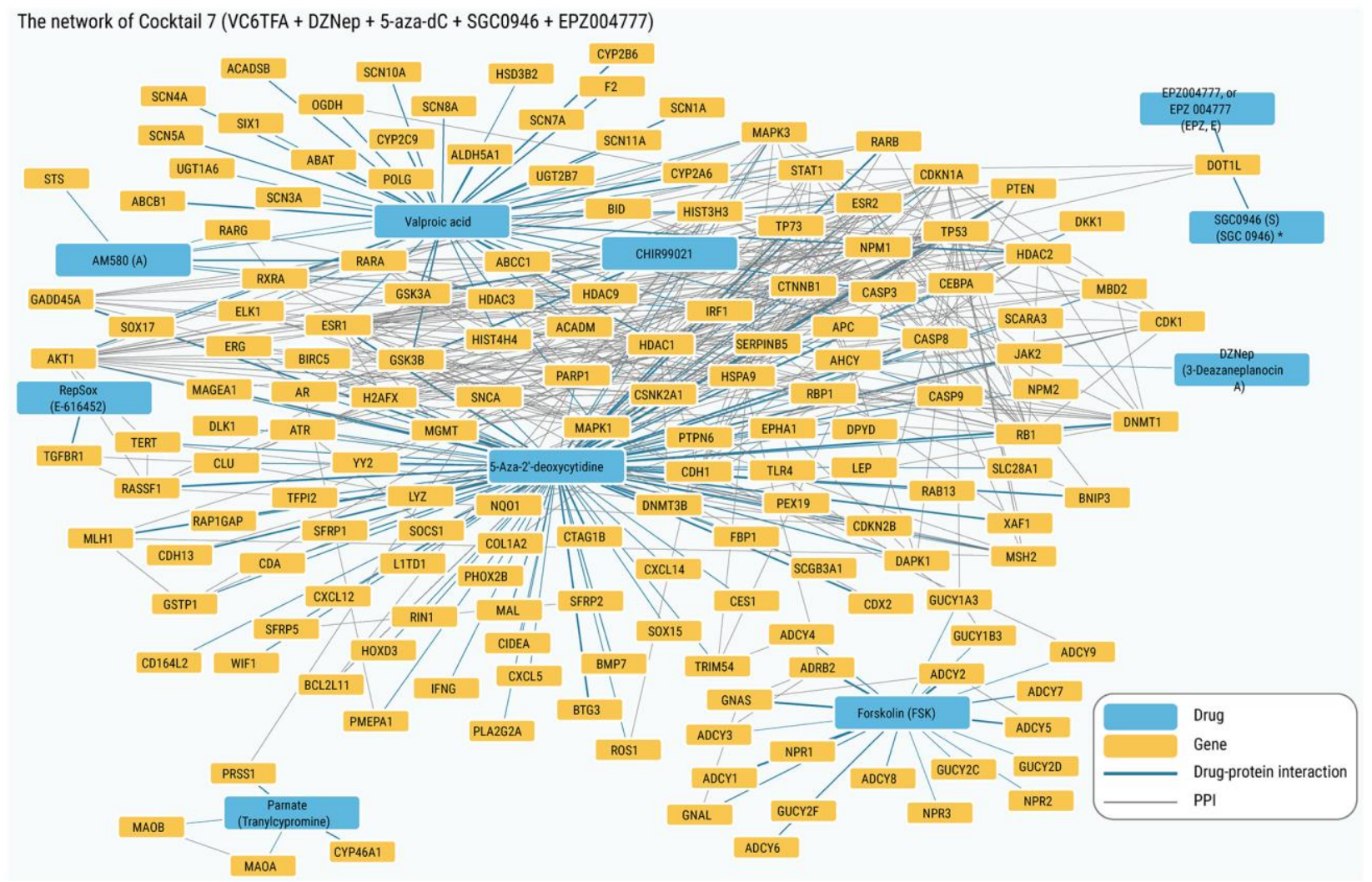

Supplementary Figure 6. The network of cocktail 7 (VC6TFA + DZNep + 5-aza-dC + SGC0946 + EPZ004777) SMs and their protein targets. 


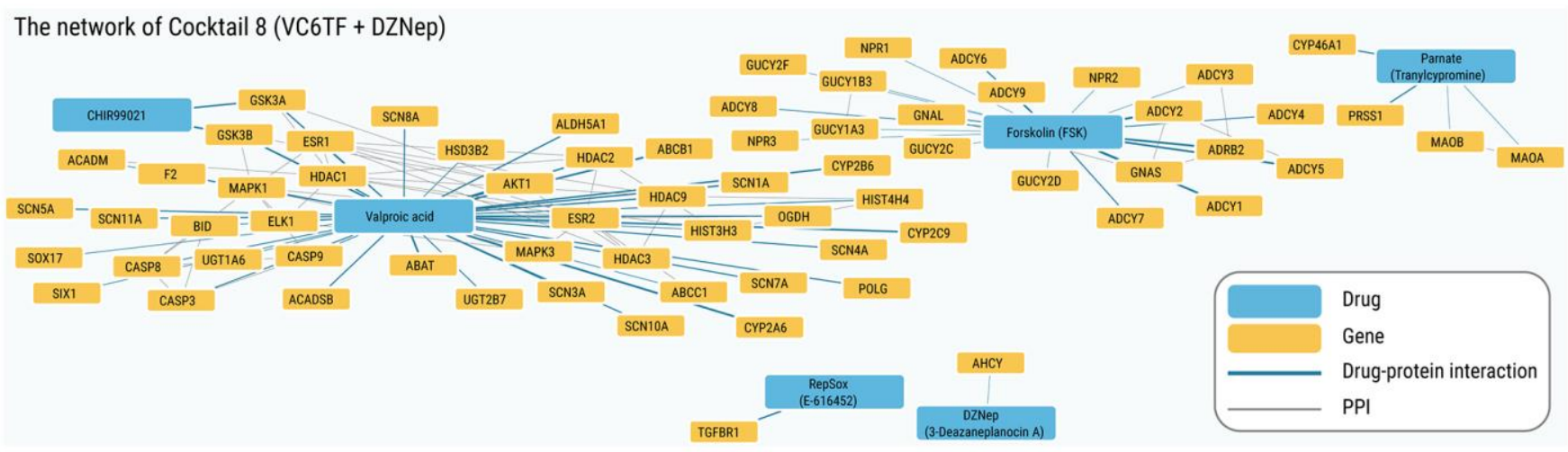

Supplementary Figure 7. The network of cocktail 8 (VC6TF + DZNep) SMs and their protein targets.

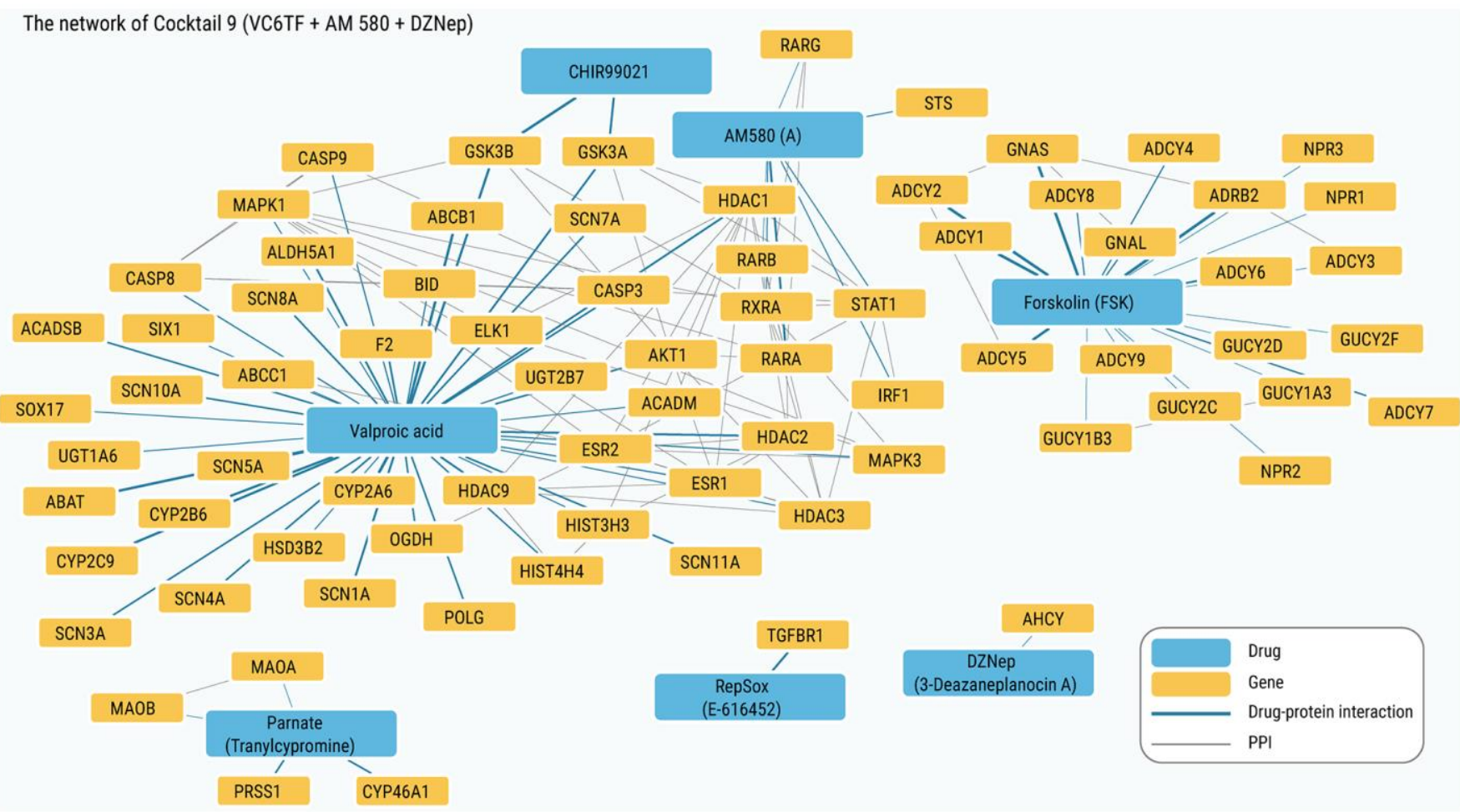

Supplementary Figure 8. The network of cocktail 9 (VC6TF + AM 580 + DZNep) SMs and their protein targets. 
The network of Cocktail 10 (CNaATP)

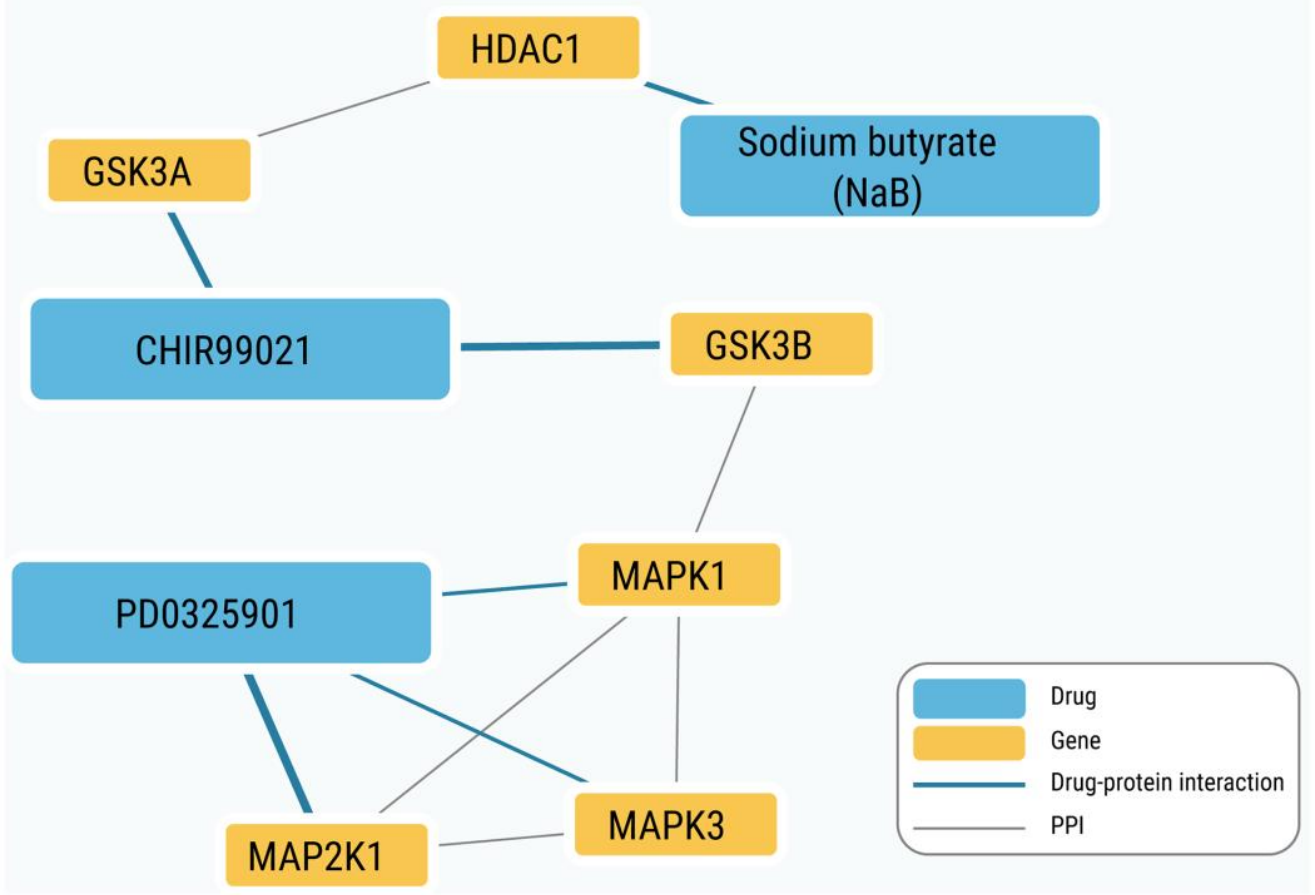

Supplementary Figure 9. The network of cocktail 10 (CNaATP) SMs and their protein targets. 


\section{Supplementary Tables}

Please browse Full Text version to see the data of Supplementary Tables 1-10.

Supplementary Table 1.92 chemical compounds.

Supplementary Table 2. SMs- signaling modifiers.

Supplementary Table 3. SMs - epigenetic modifiers.

Supplementary Table 4. SMs - metabolic modifiers.

Supplementary Table 5. SMs - other categories.

Supplementary Table 6. SM cocktails for chemical reprogramming.

Supplementary Table 7. The full list of enriched KEGG pathways of SM protein targets.

Supplementary Table 8. KEGG pathways enrichment for each SM cocktail.

Supplementary Table 9. Gene targets of all curated SMs - PPI network nodes.

Supplementary Table 10. Common targets of different SM/metabolite sets. 